\title{
Analysis of an Orthotropic Deck Stiffened with a Cement-Based Overlay
}

\author{
Walter, Rasmus; Olesen, John Forbes; Stang, Henrik; Vejrum, Tina
}

Published in:

Journal of Bridge Engineering

Link to article, DOI:

10.1061/(ASCE)1084-0702(2007)12:3(350)

Publication date:

2007

Document Version

Early version, also known as pre-print

Link back to DTU Orbit

Citation (APA):

Walter, R., Olesen, J. F., Stang, H., \& Vejrum, T. (2007). Analysis of an Orthotropic Deck Stiffened with a Cement-Based Overlay. Journal of Bridge Engineering, 12(3), 350-363. https://doi.org/10.1061/(ASCE)10840702(2007)12:3(350)

\section{General rights}

Copyright and moral rights for the publications made accessible in the public portal are retained by the authors and/or other copyright owners and it is a condition of accessing publications that users recognise and abide by the legal requirements associated with these rights.

- Users may download and print one copy of any publication from the public portal for the purpose of private study or research.

- You may not further distribute the material or use it for any profit-making activity or commercial gain

- You may freely distribute the URL identifying the publication in the public portal 


\title{
Analysis of an Orthotropic Deck Stiffened with a Cement-Based Overlay
}

\author{
Rasmus Walter*, John F. Olesen*, Henrik Stang*, \& Tina Vejrum** \\ *Department of Civil Engineering, Technical University of Denmark, DK-2800 Kgs. Lyn- \\ gby, Denmark, e-mail: rw@byg.dtu.dk
}

**COWI A/S Consultant Engineers, Parallelvej 2, DK-2800 Kgs. Lyngby, Denmark

\begin{abstract}
Over the past years, with increasing traffic volumes and higher wheel loads, fatigue damage in steel parts of typical orthotropic steel bridge decks, has been experienced on heavily trafficked routes. A demand exists to find a durable system to increase the fatigue safety of orthotropic steel bridge decks. A solution might be to enhance the stiffness of the traditional orthotropic bridge deck by using a cement-based overlay. In this paper, an orthotropic steel bridge deck stiffened with a cement-based overlay is analyzed. The analysis is based on nonlinear fracture mechanics, and utilize the finite element method. The stiffness of the steel deck reinforced with an overlay depends highly on the composite action. The composite action is closely related to cracking of the overlay and interfacial cracking between the overlay and underlying steel plate (debonding). As an example, a real size structure, the Farø Bridges located in Denmark, are analyzed. The steel box
\end{abstract}


girders of the Farø Bridges spans 80 meters, and have a depth of $3.5 \mathrm{~m}$, and a width of $19.5 \mathrm{~m}$. The focus of the present study is the top part of the steel box girders, which is constructed as an orthotropic deck plate. Numerous factors can influence the cracking behavior of the cement-based overlay system. Both mechanical and environmental loading have to be considered and effects such as shrinkage, temperature gradients and traffic loading are taken into account. The performance of four overlay materials are investigated in terms of crack widths. Furthermore, the analysis shows that debonding is initiated for a certain crack width in the overlay. The load level where cracking and debonding is initiated depends on the stress-crack opening relationship of the material.

Keywords Orthotropic bridge deck, cement-based overlay, FEM, fibre reinforced concrete, nonlinear fracture mechanics.

\section{Introduction}

Orthotropic steel bridge decks are widely used for large and medium span bridges. Compared to composite girder structures in long-span structures, the advantage of orthotropic steel decks is the considerably reduced dead load. The success of orthotropic bridge decks may be due to its high strength to weight ratio (Dowling 1968). However, compared to a rigid concrete bridge deck, a steel deck plate is subjected to considerable local deformations caused by the wheel loads on the deck. Over the years, it has been acknowledged that the record of durability on heavily trafficked routes has not been satisfactory. Fatigue damage, especially in welds and steel plates have been observed, (Kolstein \& Wardenier 1997), 
(Kolstein \& Wardenier 1998). Repairs, particularly to highway surfacing, have been necessary on many important bridges within the last 20 years or less, see e.g. Smith \& Bright (2003).

With the aim to analyze the fatigue problem in details, the mechanical behavior of orthotropic steel bridge decks has been the subject of numerous research projects over the recent years. The surfacing, and its contribution to stress reduction has, been investigated by several authors. The characteristic properties of two basic surfacing categories, bitumenous and polymeric materials, have been analyzed by Wolchuk (2002). The study shows, that for a high elastic moduli of the surfacing material, the stress range in the critical fatigue parts of the steel deck is reduced considerably. However, traditional surfacing materials are generally viscoelastic or plastic and behave elastically at low temperatures only. Experiments carried out by Jong et al. (2004) performed on orthotropic bridge decks with different surfacing materials at different temperatures, show that the stress range compared to a deck without surfacing is reduced by a factor of 1 to 6 .

A promising solution might be to use a cement-based overlay to reduce the stress range in the fatigue sensitive steel parts of an orthotropic bridge deck. This approach has already been investigated by several authors, see e.g. Battista \& Pfeil (2000) or Buitelaar et al. (2003). In practice, the first pilot test applying a cement-based overlay to an orthotropic steel bridge deck has already been carried out. A replacement of a $60 \mathrm{~m}^{2}$ area of the bascule part on the Van Breinenoord Bridge in Rotterdam, The Netherlands has been carried out, cf. Buitelaar (2002) or Jong \& Kolstein (2004). Here it is concluded that stresses in fatigue sensitive details, compared to a traditional orthotropic steel bridge 
deck, are reduced from $128 \mathrm{MPa}$ to $28 \mathrm{MPa}$. The economical investment for placing the overlay is equal to the cost of a traditional bituminous wearing course of melted asphalt. The present analysis investigates the performance of an orthotropic steel bridge deck with a cement-based overlay applied with the aim of reducing the stress range. As the composite action between the overlay and underlying steel deck is closely related to cracking, overlay cracking and debonding is the main focus of this study. Based on nonlinear fracture mechanics, modeling of cracks is carried out using the so-called Fictitious Crack Model (FCM) first presented by Hillerborg et al. (1976). The advantage of the FCM is its simplicity and good correlation with experiments.

Environmental and mechanical loading such as traffic, early age shrinkage and temperature gradients, are all significant factors which can initiate cracking. High concentrated wheel loads cause considerable local deformations of the deck. Since the overlay is bonded to the deck, local deformation caused be wheel loads produces large tensile stresses in the overlay and increases the risk of cracking. To overcome the problem of high tensile stresses in the overlay, the application of high performance concrete might be effective. However, when applying modern high performance concretes, cracking sensitivity is dramatically increased in early ages as well as in the hardened stage. Since these concretes have low water to cement ratios and often include silica fume, autogenous deformations are increased (Jensen \& Hansen 2001). Thus, an analysis of the stress history of the overlay in early ages might be important. Another important aspect, concerns the influences of temperature gradients between the overlay and steel plate. Since the overlay is restrained from moving due to its bond to the steel deck, cooling of the bridge deck produces high 
tensile stresses in the cement-based overlay. The above considerations all point towards applying ductile fiber reinforced concrete as overlay material.

Based on nonlinear fracture mechanics, this paper aims to analyze an orthotropic bridge deck stiffened with a cement-based overlay. Load effects such as mechanical and environmental loadings are considered. The aim of the study is to describe a method, which is capable of analyzing the cement-based overlay system by means of cracking behavior. Crack widths and patterns are important factors in the estimation of the durability and hence the service life of a given structural system.

\section{The Farø Bridges}

The present analysis is carried out on the Farø Bridges, which is a part of the SjællandFalster connection located in Denmark. The Farø Bridges were built between 1980 and 1985 and carries the "South Motorway" leading from Copenhagen to the European continent over waterways between the two islands Sjælland and Falster, with a small island, Farø, in the middle. The two bridges are called the Sjælland-Farø Bridge and the FarøFalster Bridge, cf. Figure 1 for a picture of the two bridges. For detailed information, see e.g. The Danish Ministry of Transportation (1987).

Fatigue problems have not yet been experienced in the orthotropic steel deck of the Far $\varnothing$ Bridges. The traffic intensity on the bridges is shown in Figure 2 for the period from 1990 to 2004. The traffic intensity on the Farø Bridges can be considered low compared to other bridges which have experienced fatigue damage in orthotropic bridge deck, cf. 
(Jong et al. 2004).

The two Farø Bridges are almost the same total length, approximately 1600 and $1700 \mathrm{~m}$, respectively, and are only separated by the small island Farø. The statical main system of the Sjælland-Falster Bridge consist of 18 spans each 80 meters long apart from the two end spans which are 78 meters long, cf. Figure 3. The southern bridge, the Farø-Falster Bridge, has a cable stayed part with a span of $290 \mathrm{~m}$. Figure 4, shows the statical main system of the Farø-Falster Bridge.

The approach spans of the Sjælland-Farø Bridge and the Farø-Falster Bridge all have a span of $80 \mathrm{~m}$. The approach spans are the focus of the present study, and thus the cable stayed part is not considered. The steel box girder designs for the two bridges are similar. The steel box girder is designed as a closed box with a trapezoidal cross-section and an all-welded orthotropic roadway deck, with a structural depth of $3.5 \mathrm{~m}$. Traffic is placed in two lanes in each direction and the steel girder has a total width of $19.6 \mathrm{~m}$, cf. Figure 5 for a cross-sectional view.

The bridge deck is designed as an orthotropic $12 \mathrm{~mm}$ deck plate provided with longitudinal trapezoidal ribs of $6 \mathrm{~mm}$ plate thickness. The ribs are $300 \mathrm{~mm}$ high and placed at $620 \mathrm{~mm}$ centres. The orthotropic deck is supported on transverse bulkheads at every 4 meters. Figure 6 displays the structural lay-out of the box girder.

\subsection{Cement-Based Overlay System}

A way to increase the local stiffness of the top orthotropic bridge deck in the steel girder might be to combine a thin cement-based overlay with the steel plate. It is suggested 
in this system to achieve composite action through adhesion and leaving out mechanical shear connectors. The motivation for leaving out shear connectors is mainly based on two reasons: (i) using shear connectors creates undesirable local peak stresses, and (ii) a system with small shear connectors in large numbers will be costly with regard to labor. Furthermore, shear connectors are only activated for large differential deformations off the two materials.

A number of small scale tests have been performed to investigate the fracture mechanical behavior of a cement-based overlay bonded to a steel plate, cf. Walter et al. (2005). Small scale tests give an initial idea of bond properties. The steel plate is sand blasted prior to casting of the overlay to ensure a good bond. Furthermore, sand blasting leaves a clean micro-rough surface and thereby the risk of bond defects is minimized. Based on experience from small scale tests, it is believed that the use of an overlay with selfcompacting properties might create a good and sound bond. Vibration of the overlay might cause water to separate from the mix, which might result in a weak interface. Similar conclusions have been drawn by Schiessl \& Zilch (2001). So far, laboratory tests on bond between steel plates and self-compacting concrete have shown surprisingly good results. The experimental steel-concrete interface studies conclude that it is possible to achieve a steel-concrete bond, which possesses fracture energy close to that of concrete. In the proposed overlay system, a typical deck consists of a 40-60 mm thick cement-based overlay bonded to the steel plate by self adhesion. An example of the proposed overlay system, with a cement-based overlay having a thickness of $50 \mathrm{~mm}$ is shown in Figure 7 along with the traditional steel deck. 
Obviously, a disadvantage of the overlay system would be increased dead load. An increase in the dead load might, at some point, require stronger members elsewhere in the structural system. In order to keep the increase in dead load at a minimum an optimization of the wearing course would be necessary. In traditional orthotropic steel bridge decks, the surfacing consists of a wearing course $(30 \mathrm{~mm})$ and an underlying intermediate layer $(25 \mathrm{~mm})$, cf. The Danish Ministry of Transportation (1987). The steel plate is of crucial importance to secure the structural system and is protected by the intermediate layer in the original system. Since a $50 \mathrm{~mm}$ thick cement-based overlay may give enough protection to the underlying steel plate, it could well be possible to replace the intermediate layer by a cement-based layer. Leaving out the intermediate layer and using a system with the cement-based overlay and an asphaltic layer on top, may be sufficient to keep the dead load at a minimum. The two surfacing systems are shown in Figure 8.

The wearing course and intermediate layer in the typical steel deck system have a total weight of approximately $1.21 \mathrm{kN} / \mathrm{m}^{2}$. In the proposed system, the intermediate layer is left out and replaced by the cement-based overlay. The total sum of weights in the proposed system is $1.76 \mathrm{kN} / \mathrm{m}^{2}$. Thus, the overlay system increases the dead load of the deck by approximately $0.55 \mathrm{kN} / \mathrm{m}^{2}$. Compared to the average dead load of the box girder on the Farø Bridges which is $8.6 \mathrm{kN} / \mathrm{m}^{2}$, the cement-based overlay system increases the dead load by $6.5 \%$. 


\section{Modeling}

The performance of the overlay system is studied based on nonlinear fracture mechanics. Numerical calculations are performed using finite elements. The orthotropic bridge deck of the 80 meter long approach spans of the Farø-Falster Bridge and the similar spans of the Sjælland-Farø Bridge are analyzed. The cable stayed part is not analyzed in the present study. The analysis of the overlay system is carried out by considering a local model of 3.9 meters times 8 meters. Exterior effects from traffic and dead load are considered in the modeling.

\subsection{Loading and Boundary Conditions}

\subsubsection{Exterior effects}

Three types of mechanical loading are considered, dead load, distributed traffic load and concentrated tandem loading. When considering a local model, exterior effects from loading are taken into account. Emphasis is put on the situation where the cementbased overlay is exposed to maximum tension, which is considered to be the most critical situation with regards to the overlay. The overlay is exposed to maximum tension where the negative bending moment will attain its maximum. The exterior forces on the local model can be found using simplified two-dimensional beam models as shown in Figure 9 . The exterior forces from traffic and dead load on the bridge can be divided into two groups as shown in Figure 9 (a) and (b). A global bending moment $M_{\text {global }}$ and shear force $V_{\text {global }}$ are found by placing uniform distributed traffic and dead load on the bridge, cf. Figure 
9(a). A statical main system of 6 spans, each having a span of 80 meters is used to find the global forces caused by traffic and dead load along the bridge. A bending moment $M_{\text {bulkhead }}$ and shear force $V_{\text {bulkhead }}$ caused by bending locally in the orthotropic deck due to the bulkheads placed every 4 meters, are also taken into account, cf. Figure 9(b). The exterior forces at the bulkhead are found by considering a statical system of 6 spans of 4 meters each. Forces found from the two dimensional beam models are then later applied to the local three dimensional model.

\subsubsection{Load}

Traffic load, denoted Uniform Distributed Load (UDL), and tandem load are chosen in accordance to ENV 1991-3 (1991). In the global bridge model, cf. Figure 9(a), a total number of four lanes are considered, where each lane has a width of $3 \mathrm{~m}$. Three lanes have an uniform distributed traffic load of $1.7 \mathrm{kN} / \mathrm{m}^{2}$, and one lane has a traffic load of 6 $\mathrm{kN} / \mathrm{m}^{2}$. The average dead load of the steel girder, including bridge equipment, has been calculated to $8.6 \mathrm{kN} / \mathrm{m}^{2}$, cf. (The Danish Ministry of Transportation 1987). The tandem system applied consists of three double-axle tandems with the following load values: 100, 200 and $300 \mathrm{kN}$.

Exterior effects caused by the bulkheads at every 4 meters, cf. Figure 9(b), are found by considering 6 spans of 4 meters each. Both the uniformly distributed load and a tandem system are taken into account. In this case the width of 3 meters (the width of one single lane) is used. From each of the two cases in Figure 9(a)-(b) a bending moment and a shear force is found. 


\subsubsection{Local Model}

The local three-dimensional model is a part of the orthotropic deck, as well as part of the bulkhead. The local orthotropic deck part considered has a height of $1.5 \mathrm{~m}$, a width of 3.9 meters and a length of $8 \mathrm{~m}$, cf. Figure 10(a). Dead load, uniform distributed load and the double-axle tandem system are applied as loads. Placement of the double-axle tandem is shown in Figure 10(a). As illustrated, the tandem pressure is applied over an area of $0.4 \times 0.4 \mathrm{~m}^{2}$. Due to symmetry, the actual modeling is reduced to a quarter of the section considered, cf. Figure 10(b). The exterior effects found previously are applied to the model as boundary conditions.

The boundary conditions of the model are shown in Figure 11. As observed in the figure, the UDL and one quarter of the double-axle tandem are applied as loads to the model. One end of the orthotropic deck, opposite the bulkhead, is modeled as a rigid plane. Exterior effects, found from Figure 9(a)-(b), are applied to the rigid plane.

\subsection{Finite Element Modeling}

A three dimensional Finite Element (FE) model using solid elements has been established. A commercial finite element software package, (DIANA 2003), has been applied. Modeling of the steel and cement-based overlay has been utilized using standard 20-node solid elements. The connection between the overlay and underlying steel deck has been modeled using an 8-node interface element available in DIANA (2003), together with a user-supplied constitutive model as described in Section 3.5. The applied element mesh 
is shown in Figure 12.

The density of the mesh has been verified using a convergence test comparing the deformation mode and stresses. The mesh shown in Figure 12, has shown to be adequate. In total the FE model of the bridge deck consists of 4108 elements.

\subsection{Steel}

According to The Danish Ministry of Transportation (1987), the main structural elements have been designed in a high yield steel quality, grade St. 52-3 N, with a yield stress of $360 \mathrm{MPa}$ and a ultimate tensile strength of $550 \mathrm{MPa}$.

Engineering constants of the steel used in the modeling work are an elastic modulus of $210 \mathrm{GPa}$ and a poisson ratio of 0.3. It is assumed, that the steel stresses in the present analysis are kept below its yield value. Furthermore, buckling of steel parts is not taken into consideration.

\subsection{Overlay Material}

The well-known advantage of fibre reinforced concrete is its ability to carry load after the first crack is formed. The fibres will typically stay unbroken after the first crack is formed and the fibres, that cross a crack, will resist further opening. Depending on the crack bridging effect, fibre reinforced composites can show different failure modes (Li \& Leung 1992). If the average fibre bridging effect is increasing during crack initiation and propagation, then multiple cracks can form. This behavior is also known as strain hardening. On the other hand, if the fibres cannot carry more load after the formation of 
the first crack, further deformation is governed by opening of a single crack. This behavior is called tension softening. In the following, both overlays of tension softening and strain hardening materials are analyzed using the FE model.

\subsubsection{Constitutive Modeling of Tension Softening Materials}

The tension softening behavior can be modeled, conceptually, by modeling a localized crack. A simple mechanical description of the localized crack in concrete was suggested by Hillerborg et al. (1976), known as the Fictitious Crack Model (FCM). A comprehensive overview of the use of nonlinear fracture mechanics for concrete structures using modeling concepts for tension softening materials is given in Karihaloo (1995).

The required constitutive input for modeling a tension softening material is the so-called stress-crack opening relationship. This relationship, expresses the amount of crack opening $w$ as a function of the stress across the crack $\sigma$. It turns out that a bilinear shape, as shown in Figure 13, correlates well to experimental data.

The stress-crack opening relationship in Figure 13 is shown normalized with respect to the uniaxial tensile strength $f_{t}$. The bilinear shape is described by two line segments, having the negative slopes $a_{1}$ and $a_{2}$, respectively. The intersection between the second line segment and the $\mathrm{y}$-axis is denoted $b_{2}$, which is a dimensionless parameter.

Application of the FCM in a FE formulation is rather straight forward. Modeling of the crack can be carried out either by the use of standard interface elements or in a continuous formulation. The continuous formulation, also known as the smeared crack approach, was formulated for concrete by Bažant \& Oh (1983). In contrast to the modeling 
of discrete cracks by using interface elements, the smeared crack approach smears out localized deformation over a characteristic length. The FE formulation is described in terms of strains instead of relative displacements.

Experimental studies investigating the behavior of tension softening materials in composite action with steel have been carried out in Walter (2005). The studies included two tension softening materials, the which constitutive parameters of which were obtained using a uniaxial test set-up similar to RILEM (2001). The uniaxial tests were used to obtain the stress-crack opening relationship in the bilinear form shown in Figure 13. The tension softening materials tested were Fibre Reinforced Concrete (FRC) and Fibre Reinforced Densitß(FRD). The average constitutive parameters obtained in the uniaxial tests for the two tension softening materials are listed in Table 1. Additionally, typical softening parameters for plain normal strength concrete are used for comparison.

In addition to the bilinear stress-crack opening parameters, the fracture energy $G_{f}$ is shown in Table 1. As observed, the fibre reinforced materials, FRC and FRD, are characterized by a much higher fracture energy than plain concrete due to their fibre contents. The FRC material in the experiments contained $1 \%, 30 \mathrm{~mm}$ long, hooked end steel fibers with a diameter of $0.5 \mathrm{~mm}$, and the FRD material contained $2 \%$ straight steel fibers with a length of $6 \mathrm{~mm}$ and a diameter of $0.16 \mathrm{~mm}$.

\subsubsection{Constitutive Modeling of Strain Hardening Materials}

The constitutive behavior of a strain-hardening material can be divided into three phases:

(i) a linear elastic phase, (ii) a multiple cracking phase, and (iii) a localization phase. The 
behavior is illustrated in Figure 14.

The second phase, the multiple cracking phase, can be described in a stress vs. strain relationship, with an ultimate tensile strength $f_{u}$ at the strain $\epsilon_{u}$. The third and final part is described in a stress-crack opening relationship, with an ultimate crack opening denoted $w_{u}$.

A strain hardening material denoted Engineered Cementitious Composite (ECC) has also been analyzed experimentally in Walter (2005). The fracture behavior of ECC were characterized using a uniaxial test set-up according to Li et al. (2002). The notation for the constitutive parameters is in accordance with Figure 14. The average parameters obtained in the tests are shown in Table 2.

As all ready mentioned the ECC material exhibits strain hardening properties when subjected to tension. The material has been engineered through a micro mechanical design approach, see e.g. Li (2002). The material tested contained $2 \%$ by volume poly-vinylalcohol (PVA) fibers, with a fibre length of $8 \mathrm{~mm}$.

\subsection{Overlay-Steel Interface}

The overlay-steel interface behavior is based on localized cracking and modeled using standard three-dimensional interface elements. An applied constitutive mixed mode model has been implemented in DIANA (2003), using user-supplied subroutines. The model is based, conceptually, on the fictitious crack model by Hillerborg et al. (1976). However, the model by Hillerborg only includes normal cracking (Mode I cracking) and does not take into account the influence of shear (Mode II cracking). The current model is an 
expansion of the FCM in three dimensions, based on a model by Wernersson (1994) and later in the three-dimensional case by Serrano (2000).

The interface is assumed to have a thickness of zero, so the stresses that should be taken into account are the normal stress and two in-plane shear stresses. Prior to cracking, linear elastic behavior is assumed, whereas after cracking, the model describes the cracking behavior as decreasing stress for increasing normal and tangential crack opening. The three stress components are, in the pure Mode I or II case, described as stress vs. crack opening in either normal or tangential direction. These three curves are coupled in the three dimensional space, so that the corresponding stiffness and stress values can be obtained for any state of mixed mode cracking.

The normal stress component $(\sigma)$ and the two shear stress components $\left(\tau_{x}\right.$ and $\left.\tau_{y}\right)$ are shown in Figure 15 along with their crack opening displacement components $\left(\delta_{n}, \delta_{t x}\right.$, and $\left.\delta_{t y}\right)$

The relation between the gradients of the six components is described through the following formula:

$$
\left[\begin{array}{c}
\dot{\sigma} \\
\dot{\tau_{x}} \\
\dot{\tau_{y}}
\end{array}\right]=\left[\begin{array}{ccc}
D_{11} & D_{12} & D_{13} \\
D_{21} & D_{22} & D_{23} \\
D_{31} & D_{32} & D_{33}
\end{array}\right]\left[\begin{array}{c}
\dot{\delta_{n}} \\
\dot{\delta_{t x}} \\
\dot{\delta_{t y}}
\end{array}\right]
$$

where the $D_{i j}$ components describe the relation between the gradients of stress and crack deformation. If the current state is elastic, the response is linear and uncoupled, hence, the off-diagonal terms of $D_{i j}$ are equal to zero. The diagonal elements are, in the elastic 
stage, assigned large values to model initial continuous geometry.

The interface behavior after peak load is obtained through the construction of a threedimensional stress-crack deformation relation. The construction is based on an assumption regarding the coupling of stress and crack deformations in three dimensions. The coefficients in Equation 1 can then be derived by differentiation. Furthermore, a general assumption in the present study is isotropy in the shear plane, so that $D_{22}=D_{33}$, $D_{32}=D_{23}, D_{21}=D_{31}$, and $D_{12}=D_{13}$

A mixed mode state can be defined using two mixed mode angles $\phi_{x y}$ and $\phi_{t n}$ :

$$
\begin{aligned}
& \phi_{x y}=\arctan \frac{\delta_{t x}}{\delta_{t y}} \\
& \phi_{t n}=\arctan \frac{\delta_{t}}{\delta_{n}}
\end{aligned}
$$

where

$$
\delta_{t}=\sqrt{\delta_{t x}^{2}+\delta_{t y}^{2}}
$$

The coupling is based on the two bilinear curves in pure Mode I and II, cf. Figure 16.

The kink points of the pure Mode I and II curves are coupled with the kink points for the current mixed mode state, by assuming the following criteria:

$$
\left(\frac{\delta_{n}^{k}}{\delta_{n}^{\max k}}\right)^{p}+\left(\frac{\delta_{t x}^{k}}{\delta_{t x}^{\text {maxk }}}\right)^{n}+\left(\frac{\delta_{t y}^{k}}{\delta_{t y}^{\max k}}\right)^{m}=1.0
$$


where $\delta_{n}^{\max k}, \delta_{t x}^{\max k}$ and $\delta_{t y}^{\max k}$ denote a kink point (defined by index $k$ ) on either the pure Mode I or II curve. The terms $\delta_{n}^{k}, \delta_{t x}^{k}$ and $\delta_{t y}^{k}$ denote a kink point on the current crack deformation curve for a given mixed mode state. The powers $p, n$ and $m$ are material constants, and are in the present study assumed to be:

$$
p=n=m=2
$$

Finally, the kink point relationship between crack deformations and stresses, in the pure Mode I or II case and the mixed mode case, are assumed to be:

$$
\begin{gathered}
\sigma^{k}=\delta_{n}^{k} \frac{\sigma^{\max k}}{\delta_{n}^{\max k}} \\
\tau_{t x}^{k}=\delta_{t x}^{k} \frac{\tau_{t x}^{\max k}}{\delta_{t x}^{\max k}} \\
\tau_{t y}^{k}=\delta_{t y}^{k} \frac{\tau_{t y}^{\max k}}{\delta_{t y}^{\max k}}
\end{gathered}
$$

The coupling can then be found using equations (5) and (7)-(9). Every kink point on the pure Mode I and II curves are linked in the three-dimensional space, so that the current stress state can be found via linear interpolation. The required input is the two bilinear curves along with the powers $p, n$ and $m$. The required bilinear curves are the pure Mode I curve $\left(\sigma-\delta_{n}\right)$, and the bilinear pure Mode II curve, which are the same in the $x$ and $y$ direction, so that the pure $\tau_{x}-\delta_{t x}$ and $\tau_{y}-\delta_{t y}$ curves are given the same input due to isotropy in the plane. After the three dimensional stress versus crack deformation relationships 
have been constructed as described above, the $D_{i j}$ terms in Equation (1) can be found by differentiation.

The input of the pure Mode I and II curves are in the current study based on experimental work carried out on concrete-steel interfaces. It has been shown in a previous study, (Walter et al. 2005), that interfacial fracture properties are close to those measured for the concrete itself. The so-called wall effect has to be taken into account, since big aggregates are not present close to the steel plate where the interfacial fracture occurs. Experimental studies have been carried out to characterize a concrete-steel interface exposed to mixed mode loading, see e.g. Walter (2005). The notation for the pure Mode I and II curves is given in Figure 16.

The constitutive properties applied are the same for all the materials analyzed in the present study, and are listed in Table 3. This is an assumption and limitation of the present study, since it would be more correct to measure the fracture properties of each individual material, FRC, FRD and ECC. The constitutive parameters applied in the study are based on experimental work on a steel-concrete interface, close to what could be measured for cement-based materials since fibres are not likely to influence the overlaysteel interface cracking. Numerical studies, analyzing the role of fracture toughness of the interface and how debonding influences the global response, has already been carried out, see e.g. Walter (2005). The conclusion is that the fracture energy of the steel-concrete interface plays a minor role and debonding is initiated for a crack mouth opening of approximately 0.03 to $0.1 \mathrm{~mm}$. 


\section{Results and Discussion}

The first study is based on linear elasticity and nonlinear effects such as overlay cracking and debonding are not considered in this part. The linear elastic study is carried out to give a simple estimate on how much the overlay contributes to stress reduction in the fatigue sensitive steel parts, when exposed to traffic load. Later in the present section an estimation of crack width and debonding based on nonlinear fracture mechanics is given. The estimation is given in terms of crack width and debonding. The nonlinear study takes into account mechanical loading along with temperature gradients between the overlay and steel structure. Finally, early-age shrinkage is modeled and discussed. Fatigue and service life is not part of the present study, however, the aspects of cyclic loading are discussed later with regards to further developments.

\subsection{Linear Elastic Studies}

One of the problems causing fatigue in traditional orthotropic steel bridge decks, is lack of transverse bending stiffness. Lack of transverse bending stiffness and the contribution to bending stiffness from the cement-based overlay can well be illustrated in a linear elastic study. Consider a double-axle tandem with an axle load of $260 \mathrm{kN}$ placed as shown previously in Figure 10, together with global traffic as outlined in Figure 9(a)-(b). The geometry of the Farø Bridges is used in the analysis and the part modeled is shown in Figure 10. Placing a double-axle tandem on the structure creates a transverse bending moment, and initiates large stresses in the welded joint between the steel plate and rib. 
This is illustrated in Figure 17, showing a deformation plot of the finite element model. The position of the wheel load is shown on the deformation plot, cf. Figure 17. As observed, the wheel load causes considerable transverse bending. Parametric studies assuming linear elasticity, using finite element calculations, have been carried out. Through a parametric study, the influences of: (i) different steel plate thicknesses, and (ii) different overlay thicknesses on a deck with a steel plate thickness of $12 \mathrm{~mm}$, are investigated. In this study, full composite action is assumed, and no debonding or cracking of the overlay is modeled. The maximum von Mises stress in the intersection between the steel plate and the rib is in focus. The results from the linear elastic study are presented in Figure 18.

The graph shows the maximum von Mises stress in the intersection between the steel plate and rib for different orthotropic deck geometries. The first parametric study investigates a pure orthotropic steel deck without any overlay. In this study, the geometry of the Far $\varnothing$ Bridges is applied, and the only modification to the original design is the thickness of the top steel plate which is the variable of the first parametric study. As seen in Figure 18, the von Mises stresses have been calculated for steel plate thicknesses of $8,12,14,16,18$, and $20 \mathrm{~mm}$. In the second parametric study, von Mises stresses have been calculated in the similar intersection, where the only modification to the original design is the application of an overlay.

The results from Figure 18 show a reduction in the von Mises stress for increasing steel plate thickness. The von Mises stress is around $300 \mathrm{MPa}$ when having a steel plate thickness of $8 \mathrm{~mm}$ and around $25 \mathrm{MPa}$ when having a steel plate thickness of $20 \mathrm{~mm}$. 
However, comparing the stress levels for that of a pure steel deck to the overlay case, it is observed that even applying a thin overlay results in a significant reduction of the von Mises stresses. Comparing the original steel design with a steel plate of $12 \mathrm{~mm}$, with systems reinforced with overlay thicknesses of $40 \mathrm{~mm}$ and $100 \mathrm{~mm}$, a stress reduction factor of 8 to 15, respectively, is achieved. The linear elastic study suggests that even a small overlay thickness leads to a significant stress reduction, since changing the overlay height from $40 \mathrm{~mm}$ to $100 \mathrm{~mm}$, only reduces the stress from $16 \mathrm{MPa}$ to $9 \mathrm{MPa}$.

Stress reductions, due to an increased stiffness by the overlay, in the weld between the rib and steel plate, have also been investigated by other authors. These investigations have been carried out through linear elastic studies and experiments. Numerical simulations on an orthotropic steel bridge deck has been reported by Buitelaar et al. (2004). This study shows a stress reduction factor of 21 in the steel plate near the rib. A paper by Jong \& Kolstein (2004), reports strain measurements on the Caland Bridge in Rotterdam, The Netherlands, prior to and after upgrading the deck with a cement-based overlay. Four weeks prior the repair work, strain gauges at various locations collected data for 4 weeks. After casting of a $50 \mathrm{~mm}$ thick overlay, the strain gauges collected additional data for 5 weeks. For strain signals caused by heavy vehicles, at the steel plate close to the rib, stress reduction factors were measured in the range of 5.9 to 7.7 .

\subsection{Cracking Behavior of Overlay due to Traffic Load}

Cracking of the overlay and debonding might be of major concern when applying a cementbased overlay to an orthotropic steel bridge deck. The aim of the nonlinear study is to 
investigate the factors that play a role in overlay cracking, and to give an estimate of the crack width and initiation of debonding. Some of the main goals in a design situation might be to minimize crack widths and to keep the solution economically feasible.

In this section, the four cement-based materials presented previously: Concrete, FRC, FRD, and ECC, are analyzed. The analysis concerns cracking pattern and crack widths due to mechanical loading. The development of cracks in the overlay for fixed traffic load and increasing axle load has been investigated utilizing finite elements. The investigation is carried out considering concrete (cf. Table 1 for constitutive parameters) as overlay material. The development of cracks for various stages of axle loads is illustrated in Figure $19(\mathrm{a})-(\mathrm{d})$

As observed in the figure, the first cracks develop in the area on top of the bulk head, denoted localized crack area no. 1, cf. Figure19(a). Even for a small axle load of approximately $52 \mathrm{kN}$, the maximum tensile stress in the concrete overlay reaches a value of $2 \mathrm{MPa}$. When further loading is applied, the maximum crack width is increased and further cracks develop. At some point, in this case for an axle load of approximately 286 $\mathrm{kN}$, cracks develop in the direction of the bridge axis. Cracking of the overlay in the direction of the bridge axis is denoted crack area no. 2, cf. Figure 19(d).

The maximum crack width for fixed traffic load, and variable tandem load, is shown in a load vs. crack width diagram, cf. Figure 20.

The figure illustrates the axle load as a function of the maximum crack width, for the four materials considered: Concrete, FRC, FRD and ECC. In the case of ECC, the results are presented as load vs. strain. In the load range considered, the maximum crack width is 
always located in crack area no. 1 as defined in Figure 19(a). In addition to the value of the crack width, initiation of cracking in crack area no. 2 (as defined in Figure 19(d)) is marked. In the load range considered, cracking only initiates in concrete and FRC in crack area no. 2. In the case of tension softening materials, increasing crack width will at some point lead to debonding. Debonding is initiated for a certain crack width which is also marked in Figure 20. It is noted that debonding is initiated at approximately the same crack width for the materials: Concrete, FRC and FRD.

\subsection{Temperature Gradients}

A temperature gradient between the overlay and underlying steel plate may give rise to tensile stresses in the overlay. Since the overlay is restrained from moving due to its bond to the steel plate, temperature gradients might play a significant role on the cracking behavior of the overlay system. Temperature gradients have to be taken into account in order to estimate the maximum crack width of the overlay. Of special concern is cooling of the bridge deck (bottom warmer than top). Since the overlay is restrained from moving, cooling of the bridge deck results in a situation with tensile stresses in the overlay. For this study, temperature gradients and thermal expansion coefficients have been chosen according to ENV 1991-2-5:1997 (1997). Thus, a thermal expansion coefficient of $10 \cdot 10^{-6} /{ }^{0} \mathrm{C}$ has been applied to the overlay. For a composite structure with a slab height of $0.2 \mathrm{~m}$, the temperature difference in a cooling situation depends on the surface thickness. It ranges from $5.9{ }^{0} \mathrm{C}$ (for unsurfaced) to $1.6{ }^{0} \mathrm{C}(200 \mathrm{~mm}$ surface). In the present analysis a parametric study is carried out lowering the temperature of the 
overlay to study cracking behavior. The applied temperature difference and distribution applied are shown in Figure 21.

The temperature in the steel part, $T_{s}$, is always set to zero degrees. The temperature difference is expressed by:

$$
\Delta T=T_{s}-T_{o}
$$

where

$$
T_{s} \equiv 0^{0} C
$$

The cracking behavior of the overlay is studied for a temperature difference $\Delta T$ of: 0 ${ }^{0} \mathrm{C}, 2.5{ }^{0} \mathrm{C}, 5{ }^{0} \mathrm{C}, 7.5{ }^{0} \mathrm{C}$, and $10{ }^{0} \mathrm{C}$. The analysis is carried out by, first, setting the temperature in the steel part, $T_{s}$, to zero degrees and changing the temperature in the overlay. After applying the temperature, fixed traffic loads are applied, and finally the tandem load is increased stepwise.

The result of the analysis for a FRC overlay is plotted in an axle load vs. crack width diagram for different temperature differences in Figure 22. As the temperature difference increases, the value of axle load that initiates cracking is lowered. For temperature differences larger than $5{ }^{0} \mathrm{C}$, cracking is initiated by the temperature loading itself. Moreover, the load levels where debonding and cracking in the direction of the bridge axis initiates are also lowered. The analysis shows that temperature differences between the overlay and steel plate influences the cracking behavior considerably and should be taken into 
account in a design situation. It should also be noted, that the wavy shaped curves in Figure 22 are due to numerical uncertainties and could be improved by decreasing the element size.

\subsection{Early Age Shrinkage}

Immediately after casting of the cement-based overlay, the cement starts to hydrate. As a consequence of hydration, the material experiences a macroscopic volume reduction known as autogenous shrinkage. Autogenous shrinkage can be quite significant in high performance concretes due to their low water to binder ratio (w/b ratio). Autogenous shrinkage plays an important role for water-cement ratios below $0.40-0.45$ (Jensen \& Hansen 2001). The magnitude of autogenous shrinkage has been measured, on cement paste, of more than 1000 micro strains after a few weeks of hardening, (Jensen \& Hansen 2001). Since the overlay is restrained from moving, due to its bond with the steel plate, shrinkage may cause cracking and early age performance has to be taken into account. Proper curing conditions should be established, since poor curing conditions may cause additional shrinkage, known as drying shrinkage. In the following, autogenous shrinkage is the main focus, as this is hard to avoid, when using high performance concretes. In this section, a short introduction to the applied modeling framework will be given, with the aim to analyze the shrinkage behavior and risk of cracking at early ages. Given a shrinkage history, it is the aim of the study to give an estimate of the risk of cracking and the stress level in the overlay at a given time. Creep of the overlay is a significant factor at early age and has to be taken into account. 


\subsubsection{Shrinkage Function}

An expression for the autogenous shrinkage over time, based on experimental data, has been proposed by the Japanese Concrete Institute (Tazawa et al. 2000). Shrinkage as a function of time can be found by the following expression:

$$
\epsilon_{\text {shrinkage }}(t)=\left[\gamma \epsilon_{\text {inf }}(w / b) \beta(t)\right] 10^{-6}
$$

where $\gamma$ is a coefficient to describe the effect of cement type $(\gamma=1$ for ordinary Portland Cement), $\epsilon_{i n f}(w / b)$ is the ultimate autogenous shrinkage. The ultimate autogenous shrinkage is a function of the water-binder ratio $w / b$, and can be found from $\epsilon_{\text {inf }}(w / b)=3070 \exp (-7.2(w / b))$. The development of shrinkage over time is described by $\beta(t)$ in the following form:

$$
\beta(t)=\left[1-\exp \left(-a\left(t-t_{0}\right)^{b}\right)\right]
$$

where $t_{0}$ is the initial setting time. The two remaining variables $a$ and $b$ are constants.

\subsubsection{Modeling of Creep}

As discussed earlier, autogenous shrinkage in the overlay causes tensile stresses in the overlay. Moreover, when applying a constant stress over time in a cement-based material, relaxation of the material needs to be taken into account. As the cement-based material is exposed to a constant stress over time, the stresses will decline with time. This behavior can be described by viscoelasticity and various models can be applied to describe the 
viscoelastic behavior of cement-based materials. In this study, a Kelvin chain is applied, for modeling of shrinkage and creep. Bažant (1988) gives a full detailed review of creep modeling in cement-based materials. For clarity of the modeling and to make the paper self-contained, a short introduction is given to the applied model. The Kelvin chain model is based on a unique compliance function $J\left(t, t^{\prime}\right)$, which predicts the time dependent deformations as function of time of load application $t^{\prime}$ and the duration of load $\left(t-t^{\prime}\right)$. The compliance function is expressed as:

$$
J\left(t, t^{\prime}\right)=\frac{1}{E_{0}\left(t^{\prime}\right)}+\frac{1}{E_{1}\left(t^{\prime}\right)} H_{1}\left(t, t^{\prime}\right)+\frac{1}{E_{2}\left(t^{\prime}\right)} H_{2}\left(t, t^{\prime}\right)+\ldots+\frac{1}{E_{n}\left(t^{\prime}\right)} H_{n}\left(t, t^{\prime}\right)
$$

where $t$ is time, $E_{0}\left(t, t^{\prime}\right)$ is the instantaneous elastic deformation, for the load applied at an age of $t^{\prime}$. The function $H_{n}\left(t, t^{\prime}\right)$ is given by:

$$
H_{n}\left(t, t^{\prime}\right)=1-\exp \left(\frac{t^{\prime}-t}{\tau_{n}}\right)
$$

where $\tau_{n}$ is the so-called retardation time of chain unit $n$. The link between the retardation time and the viscosity of the dashpot $\eta_{n}$, is given by:

$$
\tau_{n}=\frac{\eta_{n}}{E_{n}}
$$

The development of the modulus of elasticity over time, as included in Equation (14), can be expressed by the following function:

$$
E(t)=A_{1}\left[1-e^{-\left(t / \tau_{1}\right)^{n_{1}}}\right]+A_{2}\left[1-e^{-\left(t / \tau_{2}\right)^{n_{2}}}\right]
$$


where $n_{i}$ is a dimensionless factor related to geometry of the problem.

Experimental creep properties obtained by Østergaard (2003) are applied in this study. He conducted experiments at $t^{\prime}=1,3$ and 5 days. The fit to experimental values have been obtained by using a 4 chain unit, cf. Figure 23 .

The Kelvin Chain consists of 4 units, all of them with a spring, and three units have a dashpot. The spring values, according to Equation (17), are listed in Table 4. The dashpot parameters to the three units are given in Table 5.

\subsubsection{FE Modeling of Shrinkage and Creep}

Viscoelasticity of cement-based materials can be modeled using finite elements. In the present study modeling is carried out using a Kelvin chain, which is implemented in DIANA (2003). To illustrate an overlay cast on a steel plate a small example is analyzed. An infinity long specimen is considered, with a thickness of $50 \mathrm{~mm}$, bonded to a steel plate, exposed to shrinkage over time. The investigation aims at calculating the stresses as a function of time. Since the modulus of elasticity and creep properties develop over time, the material is given the creep properties shown previously. The infinity long specimen is analyzed through a parametric study. The specimen is given four different shrinkage histories using Equation (12). As an example, a water binder ration is chosen to 0.45, an ordinary Portland Cement $(\gamma=1)$, and a constant $b$ value $(b=1)$. The constant $a$ is varied according to: $a=0.3,0.5,0.7,0.9$.

The results of the analysis, varying the shrinkage history, are shown in Figure 24. Figure 24(a), shows the four different shrinkage histories, computed varying the constant $a$ in 
formula (12). As observed, in all the cases, the curves all end at the same ultimate shrinkage value. However, a low value of the constant $a$, produces a more slow approach to the ultimate shrinkage value. The corresponding responses of the stress level in the specimen are shown in Figure 24(b). As seen, the four cases produce quite different responses. In the case of a low value of the constant $a$, the maximum stress level becomes quite large compared to the other cases. Moreover, the rate of stress drop is slower over time, which is caused by the fact that relaxation of a cement-based material is largest in the first few hours after casting. Since the magnitude of relaxation is large at this stage, it is ideal to have autogenous shrinkage developing here.

In relation to the present overlay application, the development of the tensile stresses and the risk of cracking have to be taken into account. Too large shrinkage values at early ages might exceed the tensile strength and thereby cause cracking. Another aspect is the stress level when the bridge is opened for traffic. A considerable stress level may have to be considered along with traffic and temperature load in order to give an estimate of the overlay performance. In a given design situation, different shrinkage levels should be applied to the overlay together with traffic and temperature loading.

\section{$5 \quad$ Further Investigations}

Cyclic loading has not been analyzed in the present study, but should be a part of a full assessment of the cement-based overlay system. The maximum crack width will increase for a certain number of cycles, which has not been taken into account. At present, a 
number of fracture mechanical studies on the fatigue behavior of cement-based materials have been carried out, see e.g. Matsumoto \& Li (1999) or Zhang et al. (2001). In order to estimate the service life of the overlay system, the influence of load cycles should be implemented in the constitutive models applied.

\section{Conclusions}

One of the main causes of fatigue in orthotropic steel bridge decks is their lack of stiffness. In a linear elastic study using finite elements it has been shown, that applying a cementbased overlay results in a significant and in many cases sufficient reduction of stresses in the fatigue sensitive steel regions.

The cement-based overlay system for stiffening a traditional orthotropic steel bridge deck has been analyzed applying nonlinear fracture mechanics. The investigation concerns the orthotropic bridge deck of the steel box girders of the approach spans of the Farø Bridges, Denmark. The focus is on the situation with maximum negative bending (tension in the overlay), since this situation is believed to be critical to the overlay. Performance of the overlay might be closely related to cracking and debonding. Cracking behavior of the overlay system has been analyzed for four different materials. The materials investigated are: plain concrete, Fibre Reinforced Concrete (FRC), Fibre Reinforced Densit@(FRD), and Engineered Cementitious Composite (ECC). Concrete, FRC and FRD can be classified as tension softening materials, whereas ECC is characterized as a strain hardening material. 
Cracking and eventually debonding is initiated due to mechanical and environmental loading. Mechanical loading (traffic) and environmental loading such as early age shrinkage and temperature gradients have been analyzed. A double axle tandem system placed across the bulkhead initiates cracking of the overlay due to large tensile stresses. At some point (for a certain crack width in the overlay) debonding is initiated and develops perpendicular and away from the bulkhead. When comparing the performance of the different tension softening materials, debonding is initiated at approximately the same crack mouth opening in the overlay. Debonding is not initiated for the strain hardening material analyzed, ECC. Further loading of the tandem system initiates cracking perpendicular to the bridge axis. In the load range considered, cracking perpendicular to the bridge axis is only initiated for the tension softening materials. The analysis shows that applying a cement-based material that exhibits multiple cracking is desirable due to the fact that debonding can be avoided in the load range considered.

Temperature gradients might have a significant influence on the performance of the cement-based overlay system. Cooling of the overlay (bottom warmer than top), produces tensile stresses in the overlay since it is restrained from moving because of its bond to the steel deck. For different temperature gradients and tandem load the performance of the overlay system is shown in terms of crack width. Again, debonding is initiated across the bulkhead for a certain crack mouth opening.

Finally, it is demonstrated how early age shrinkage can be taken into account. After casting of the overlay, high tension stresses develop in the overlay due to macroscopic volume changes. In the worst case, cracking might be initiated due to early age shrinkage, 
or high tensile stresses may be present when the bridge is opened for traffic.

\section{References}

Battista, R. \& Pfeil, M. (2000), Stranghening fatigue cracked orthotropic decks with composite layers, in 'Annual Technical Sesseion, and Meetin, Structural Stability Research Council', pp. 376-389.

Bažant, Z. P. (1988), Mathematical Modeling of Creep and Shrinkage of Concrete, UK: John Wiley.

Bažant, Z. P. \& Oh, B. H. (1983), 'Crack band theory for fracture of concrete', Materials and Structures 16, 155-157.

Buitelaar, P. (2002), Ultra thin heavy reinforced high performance concrete overlays, in '6th International Symposium on Utilization of High Strength / High Performance Concrete, Leipzig, Germany', pp. 1577-1590.

Buitelaar, P., Braam, C. R. \& Kaptaijn, N. (2003), Reinforced high performance concrete overlay system for steel bridges, in 'In the 5th International CROW-Workshop on Fundamental Modelling of the Design and Performance of Concrete Pavements, Istanbul, Turkey'.

Buitelaar, P., Braam, R. \& Kaptijn, N. (2004), Reinforced hig performance concrete overlay system for rehabilitation and strengthening of orthotropic steel bridge decks, in 'Orthotropic Bridge Conference, Sacremento, USA', ASCE, pp. 384-401. 
DIANA (2003), DIANA User's Manual - Release 8.1, june edn, TNO Building and Construction Research, P.O. Box 49, 2600 AA Delft, The Netherlands.

Dowling, P. J. (1968), The Behaviour of Stiffened Plate Bridge Deck under Wheel Loading, PhD thesis, Imperial College London.

ENV 1991-2-5:1997 (1997), Eurocode 1 - Actions on Structures - Part 1-5: General Actions - Thermal Actions, European Commitee for Standardisation.

ENV 1991-3 (1991), Eurocode 1 - Basis of Design and Actions on Structures, Part 3: Traffic Loads on Bridges, European Commitee for Standardisation.

Hillerborg, A., Modéer, M. \& Petersson, P. (1976), 'Analysis of crack formation and crack growth in concrete by means of fracture mechanics and finite elements', Cem. Concr. Res. 6(6), 773-782.

Jensen, O. M. \& Hansen, P. F. (2001), 'Autogenous shrinkage and RH-change in perspective', Cement and Concrete Research 31(12), 567-575.

Jong, F. B. P. \& Kolstein, M. H. (2004), Strenghening a bridge deck with high performance concrete, in 'Orthotropic Bridge Conference, Sacremento, USA', ASCE, pp. 328-347.

Jong, F. B. P., Kolstein, M. H. \& Bijlaard, F. S. K. (2004), Strain measurement tests at orthotropic steel bridge decks with a heavy vehicle simulator, in 'Prooceddings of the 10th Nordic Steel Construction Conference, Copenhagen, Denmark', pp. 401-412. 
Karihaloo, B. L. (1995), Fracture Mechanics and Structural Concrete, Concrete Design and Construction Series, Longman Scientific and Technical, Harlow, Essex, England.

Kolstein, M. H. \& Wardenier, J. (1997), 'Stress reduction due to surfacing on orthotropic steel decks', IABSE Workshop, IABSE Reports, Vol. 76, Zurich, Lausanne .

Kolstein, M. H. \& Wardenier, J. (1998), A new type of fatigue failures in steel orthotropic bridge decks, in 'Proceedings of the fifth Pacific Structural Conference, Korea', pp. 483-488.

Li, V. (2002), 'Advances in ECC research', ACI Special Publication on Concrete: Material Science to Applications SP 206(23), 463-472.

Li, V. C. \& Leung, C. K. Y. (1992), 'Steady-state and multiple cracking of short random fiber composites', Journal of Engineering Mechanics 118(11), 2246-2264.

Li, V., Wu, C., Wang, S., Ogawa, A. \& Saito, T. (2002), 'Interface tailoring for strainhardening PVA-ECC', ACI Materials Journal 99(5), 373-400.

Matsumoto, T. \& Li, V. C. (1999), 'Fatigue life analysis of fiber reinforced concrete with a fracture mechanics based model', Cement and Concrete Composites 21(4), 249-261.

Østergaard, L. (2003), Early-Age Fracture Mechanics and Cracking of Concrete. Experiments and Modelling, PhD thesis, Department of Civil Engineering, Technical University of Denmark, Lyngby, Denmark. 
RILEM (2001), 'Test and design methods for steel fiber reinforced concrete. recommendations for uniaxial tension test', Materials and Structures 34(3-6). Prepared by RILEM-Committee-TDF-162, Chairlady L. Vandewalle.

Schiessl, A. \& Zilch, K. (2001), 'The effect of the modified composition of SCC on shear and bond behavior', Proceedings of the Second International Symposium on selfCompacting Concrete, Tokyo pp. 501-506.

Serrano, E. (2000), 'Adhesive joints in timber engineering - modelling and testing of fracture properties', Doctoral Thesis, Lund University, Division of Structural Mechanics

Smith, J. W. \& Bright, S. (2003), Upgrading orthotropic bridge decks with fiber reinforced composites, in 'High Performance Materials in Bridges', pp. 463-472.

Tazawa, E., Sato, R., Sakai, E. \& Miyazawa, S. (2000), Work of JCI commitee on autogenous shrinkage, in V. Baroghel-Bouny \& P. C. Aitcin, eds, 'Shrinkage of Concrete, International RILEM Workshop', Vol. PRO 17.

The Danish Ministry of Transportation (1987), 'The superstructure of the farø bridges 1. design of the steel superstructure', The Danish Ministry of Transportation, The Road Directorate, ISBN 87-7491-238-0 .

Walter, R. (2005), Cement-Based Overlay for Orthotropic Steel Bridge Decks - A MultiScale Modeling Approach, PhD thesis, Department of Civil Engineering, Technical University of Denmark, Lyngby, Denmark. 
Walter, R., Østergaard, L., Olesen, J. F. \& Stang, H. (2005), 'Wedge splitting test for a steel-concrete interface', Journal of Engineering Fracture Mechanics 72(17), 25652583.

Wernersson, H. (1994), 'Fracture characterization of wood adhesive joints', Report TVSM1006, Lund University, Division of Structural Mechanics .

Wolchuk, R. (2002), 'Structural behaviour of surfacing on steel orthotropic decks and considerations for practical design', Structural Engineering International 2, 124-129.

Zhang, J., Stang, H. \& Li, V. C. (2001), 'Crack bridging model for fibre reinforced concrete under fatigue tension', International Journal of Fatigue 23(8), 655-670.

\section{Notation}

$\begin{array}{ll}\beta(t) & \text { function to describe the development of shrinkage } \\ \delta_{n} & \text { crack opening in normal plane } \\ \delta_{t x} & \text { tangential crack opening in x-direction } \\ \delta_{t y} & \text { tangential crack opening in y-direction } \\ \delta_{t} & \text { resulting tangential crack opening in t-plane } \\ \epsilon_{e} & \text { elastic strain limit for strain hardening material } \\ \epsilon_{\text {inf }}(w / b) & \text { ultimate autogenous shrinkage } \\ \epsilon_{s h r i n k a g e} & \text { shrinkage strain } \\ \epsilon_{u} & \text { ultimate strain limit for strain hardening material }\end{array}$




\begin{tabular}{|c|c|}
\hline$\eta$ & viscosity \\
\hline$\gamma$ & coefficient in shrinkage formulation \\
\hline$\phi_{t n}$ & mixed mode angle in the $t-n$ plane \\
\hline$\phi_{x y}$ & mixed mode angle in the $x-y$ plane \\
\hline$\sigma$ & normal stress \\
\hline$\tau$ & retardation time \\
\hline$\tau$ & shear stress \\
\hline$\tau_{x}$ & shear stress in $\mathrm{x}$-direction \\
\hline$\tau_{y}$ & shear stress in $\mathrm{y}$-direction \\
\hline$A$ & material constant \\
\hline$a$ & constant \\
\hline$a_{1}, a_{2}, b_{1}, b_{2}$ & parameters in the bilinear stress-crack opening relationship \\
\hline$b$ & constant \\
\hline$D_{i j}$ & stiffness components for interface description \\
\hline$E$ & modulus of elasticity \\
\hline$f_{t}$ & tensile strength \\
\hline$f_{u}$ & ultimate tensile strength \\
\hline$G_{f}$ & fracture energy \\
\hline$H$ & function \\
\hline$J$ & compliance \\
\hline
\end{tabular}




$\begin{array}{ll}M, m, p & \text { bending moment } \\ T & \text { material exponents } \\ & \text { temperature } \\ t & \text { thickness of steel plate } \\ t & \text { time } \\ t_{0} & \text { initial setting time } \\ V & \text { shear force } \\ & \text { crack opening } \\ w_{u} & \text { crack opening limits in the bilinear stress-crack opening relationship (overlay) } \\ w_{1}, w_{2} & \text { ultimate crack opening for strain hardening material } \\ & \end{array}$

\begin{tabular}{|l|c|c|c|c|c|}
\hline Material & $\begin{array}{c}f_{t} \\
{[\mathrm{MPa}]}\end{array}$ & $a_{1}$ & $a_{2}$ & $b_{2}$ & $G_{f}$ \\
{$\left[\mathrm{~mm}^{-1}\right]$} & {$\left[\mathrm{mm}^{-1}\right]$} & {$[-]$} & {$[\mathrm{N} / \mathrm{mm}]$} \\
\hline FRC & 2.3 & 27 & 0.50 & 0.35 & 0.30 \\
FRD & 4.8 & 64 & 0.57 & 0.46 & 0.90 \\
Concrete & 2.0 & 50 & 1.0 & 0.1 & 0.03 \\
\hline
\end{tabular}

Table 1: Constitutive parameters of three tension softening materials analyzed as overlay material. Parameters are based on values from Walter et al. (2004). 


\begin{tabular}{|l|c|c|c|c|}
\hline Material & $f_{t}$ & $f_{u}$ & $\epsilon_{u}$ & $w_{u}$ \\
{$[\mathrm{MPa}]$} & {$[\mathrm{MPa}]$} & {$[\%]$} & {$[\mathrm{mm}]$} \\
\hline ECC & 4.2 & 5.3 & 1.9 & $4^{*}$ \\
\hline
\end{tabular}

Table 2: Constitutive parameters of a strain hardening material ECC (*Note this value is an assumption). Parameters are based on values from Walter et al. (2004).

\begin{tabular}{|l|c|c|c|c|c|}
\hline Mode I & $\sigma^{\max 1}[\mathrm{MPa}]$ & $\sigma^{\max 2}[\mathrm{MPa}]$ & $\delta_{n}^{\max 2}[\mathrm{~mm}]$ & $\delta_{n}^{\max 3}[\mathrm{~mm}]$ & $G_{f}[\mathrm{n} / \mathrm{mm}]$ \\
n-direction & 3.0 & 0.4 & 0.02 & 0.5 & 0.12 \\
\hline Mode II & $\tau_{x}^{\max 1}[\mathrm{MPa}]$ & $\tau_{x}^{\max 2}[\mathrm{MPa}]$ & $\delta_{t x}^{\max 2}[\mathrm{~mm}]$ & $\delta_{t x}^{\max 3}[\mathrm{~mm}]$ & $G_{f}[\mathrm{n} / \mathrm{mm}]$ \\
tx-direction & 3.5 & 0.5 & 0.02 & 0.77 & 0.23 \\
\hline Mode II & $\tau_{y}^{\max 1}[\mathrm{MPa}]$ & $\tau_{y}^{\max 2}[\mathrm{MPa}]$ & $\delta_{t y}^{\max 2}[\mathrm{~mm}]$ & $\delta_{t y}^{\max 3}[\mathrm{~mm}]$ & $G_{f}[\mathrm{n} / \mathrm{mm}]$ \\
ty-direction & 3.5 & 0.5 & 0.02 & 0.77 & 0.23 \\
\hline
\end{tabular}

Table 3: Pure Mode I and II parameters (Figure 16) based on values from Walter \& Olesen (2005), used as constitutive interface parameters. Note that $\delta_{n}^{\max 1}$ and $\delta_{t y}^{\max 1}=\delta_{t x}^{\max 1}$ are assigned a small value for numerical reasons. 


\begin{tabular}{l|cccc} 
& $E_{0}$ & $E_{1}$ & $E_{2}$ & $E_{3}$ \\
\hline$A_{1}[\mathrm{GPa}]$ & 43.4 & 180 & 280 & 360 \\
$\tau_{1}[$ hours $]$ & 23.9 & 5 & 50 & 500 \\
$n_{1}[-]$ & 2.19 & 1 & 1 & 1 \\
$A_{2}[\mathrm{GPa}]$ & 20.0 & - & - & - \\
$\tau_{2}[\mathrm{hours}]$ & 100 & - & - & - \\
$n_{2}[-]$ & 4 & - & - & -
\end{tabular}

Table 4: Fitting parameters of the springs in the applied Kelvin Chain

\begin{tabular}{c|ccc} 
& $H_{1}$ & $H_{2}$ & $H_{3}$ \\
\hline$\tau_{n}[$ hours $]$ & 50 & 5 & 500
\end{tabular}

Table 5: Fitting parameters of the three dashpots in the applied Kelvin Chain

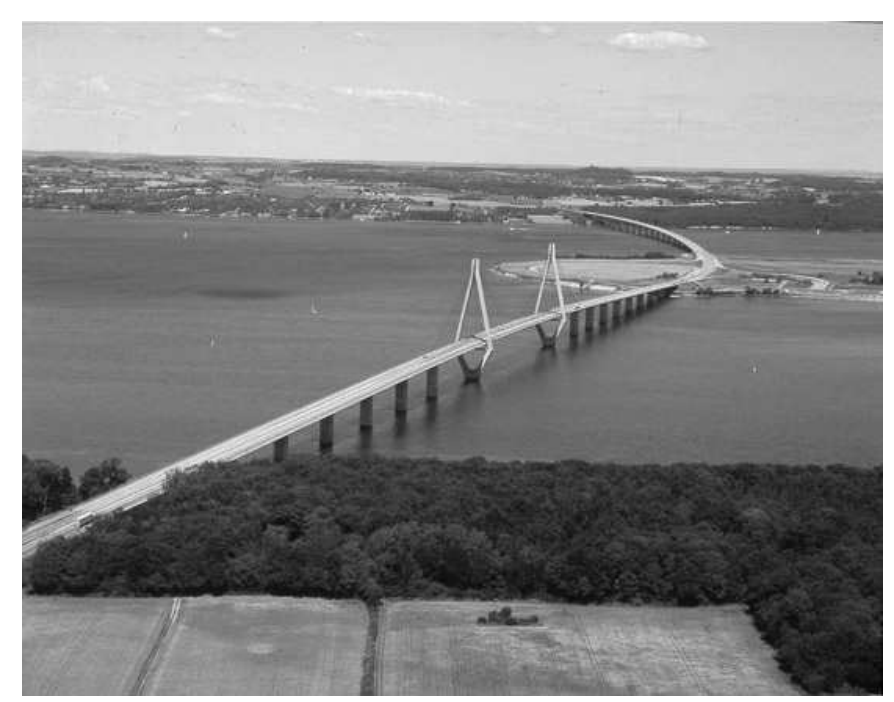

Figure 1: The Farø Bridges. 


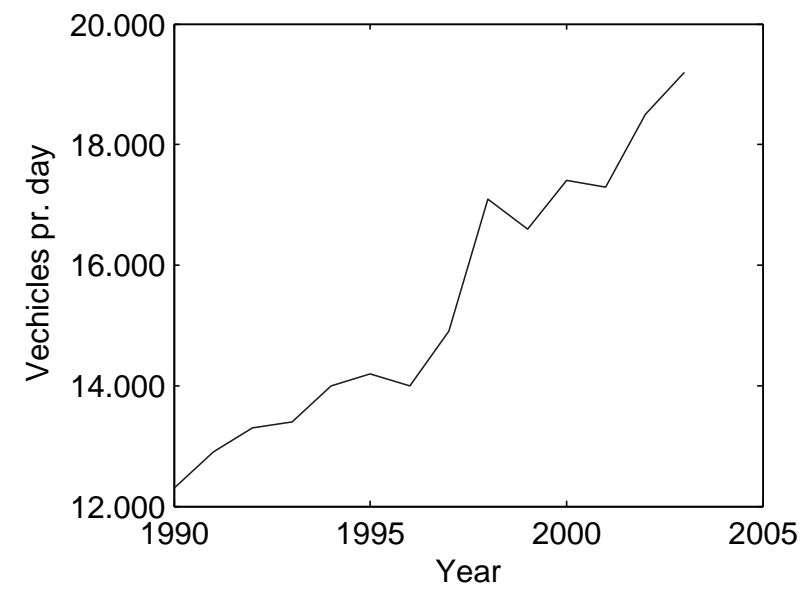

Figure 2: Traffic intensity on the Farø Bridges, source: (Danish Ministry of Transportation, www.vd.dk). 
Elevation

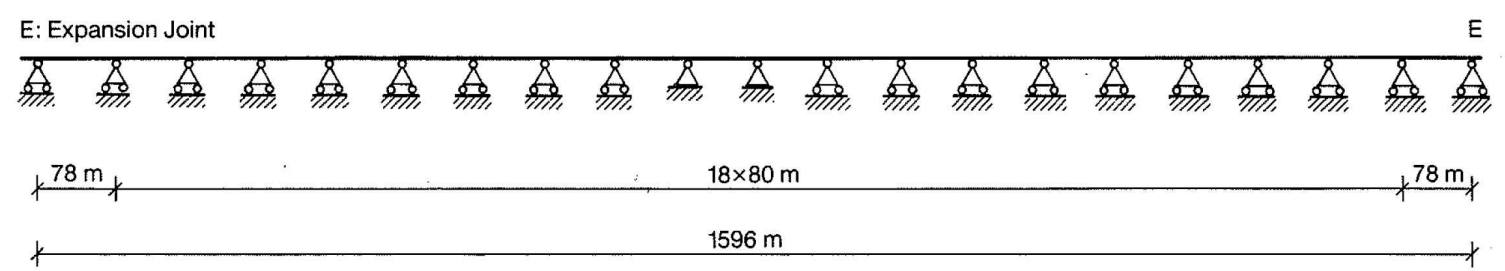

Figure 3: Statical main system, the Sjælland-Farø Bridge. 
Elevation

E: Expansion Joint

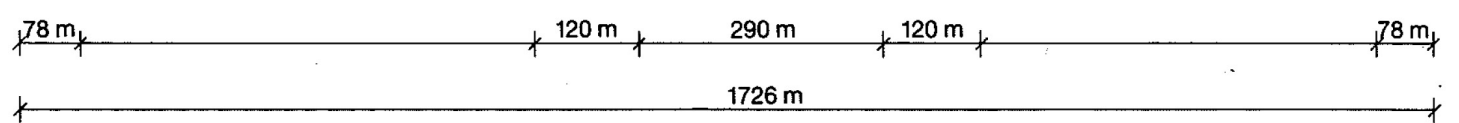

Figure 4: Statical main system, the Farø-Falster Bridge. 


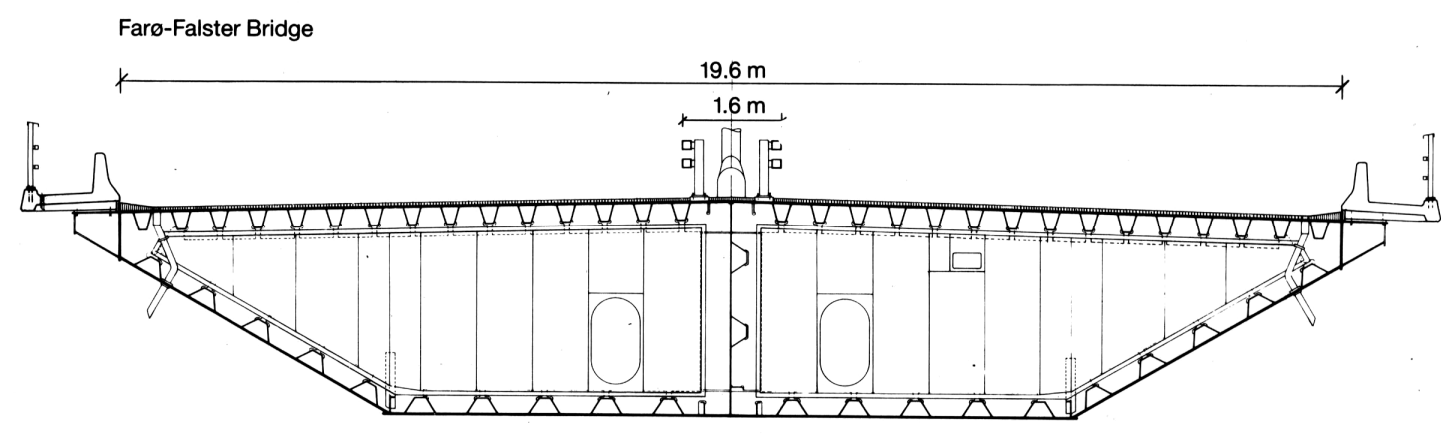

Figure 5: Cross-sectional view of the steel girder of the Farø Bridges. 


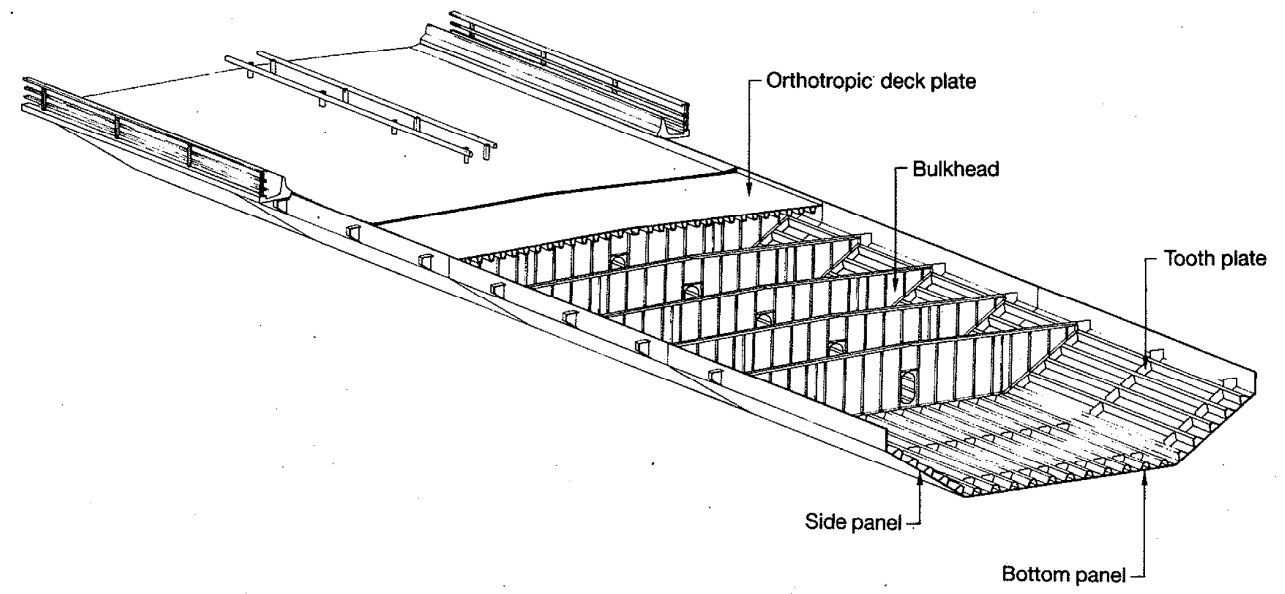

Figure 6: Box girder, structural principle. Bulkheads every $4 \mathrm{~m}$. 


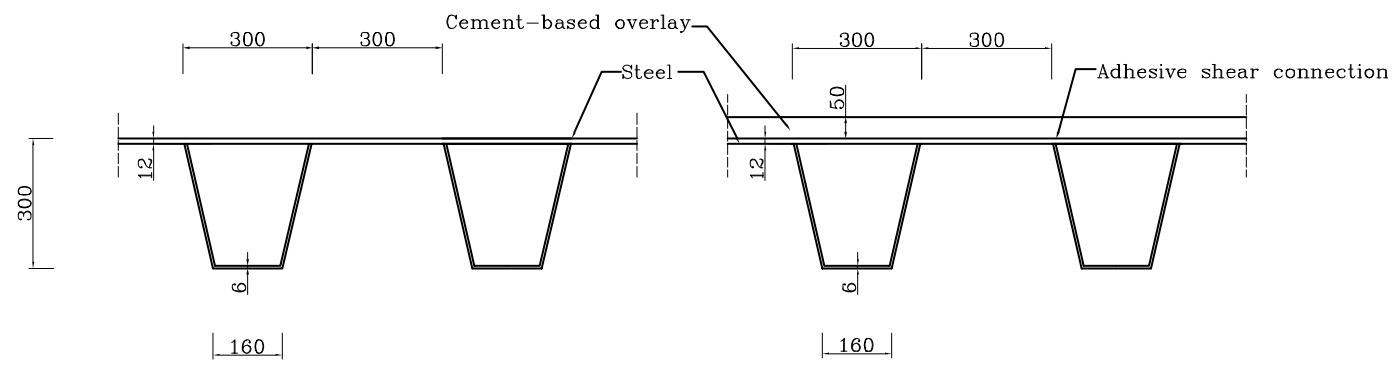

Figure 7: (a) Typical steel system, with a center span of $300 \mathrm{~mm}$ between the supporting ribs and a $12 \mathrm{~mm}$ steel plate. (b) Cement-based overlay system with a $50 \mathrm{~mm}$ thick cement-based overlay. 


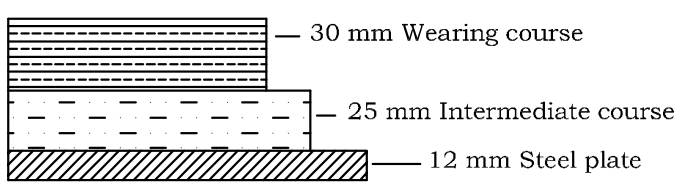

(a)

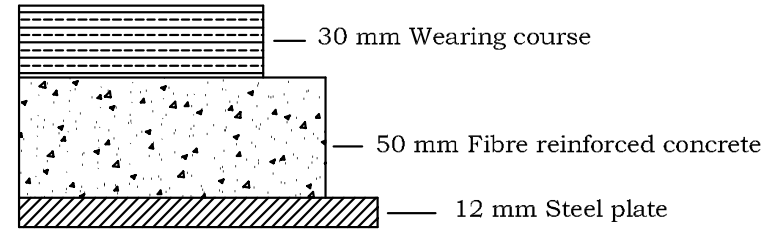

(b)

Figure 8: (a) Detail showing typical surfacing for an orthotropic steel bridge deck (b) Proposed system using a steel plate and a layer of cement-based material acting as a composite and a $30 \mathrm{~mm}$ wearing course on top. 


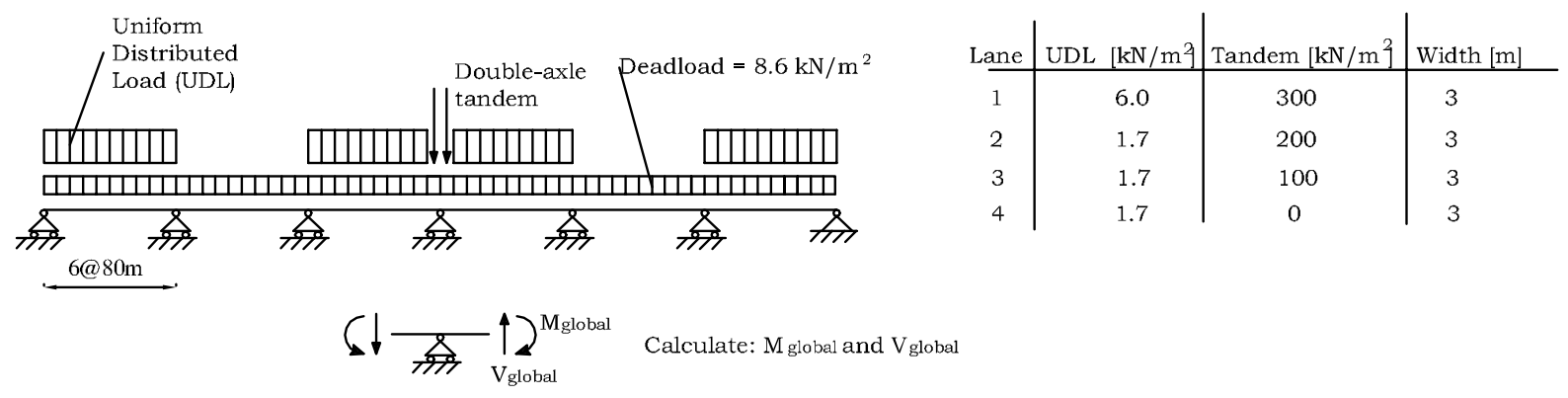

(a)

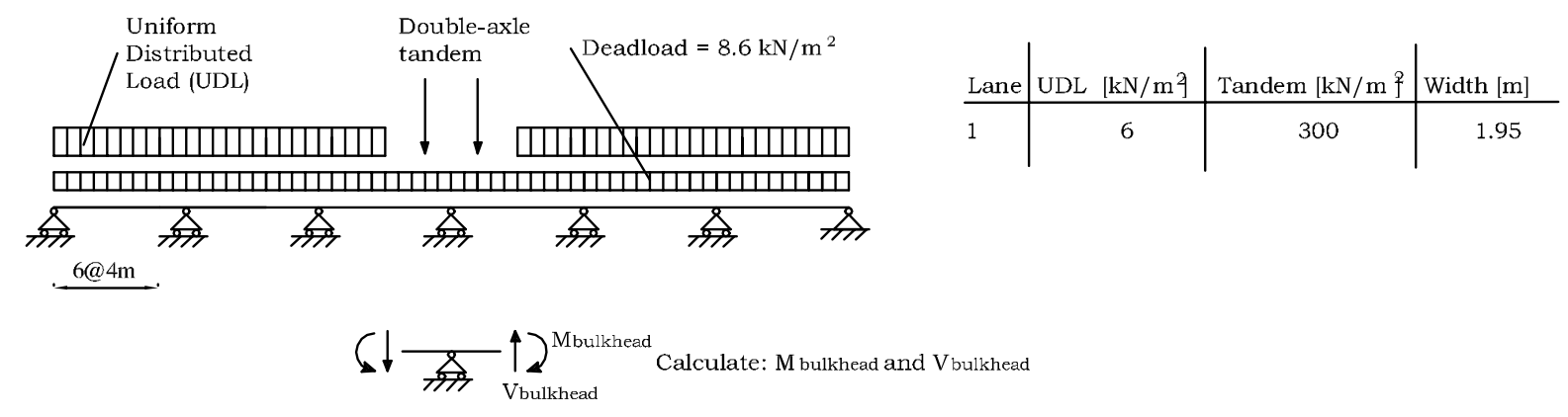

(b)

Figure 9: (a) Global model to calculate exterior effects on the local model from traffic and dead load. A bending moment $M_{\text {global }}$ and shear force $V_{\text {global }}$ are found. A total number of 6 spans are taken into account and 4 traffic lanes are used. (b) Model to calculate exterior forces, $M_{\text {bulkhead }}$ and $V_{\text {bulkhead }}$, caused by bulkheads placed at every 4 meters. A total number of 6 spans of 4 meters and one traffic lane is taken into account. 


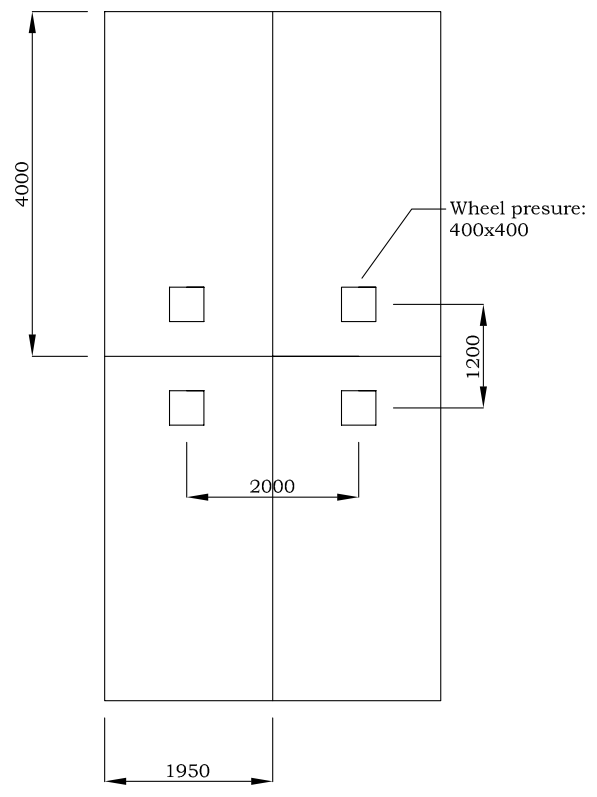

(a)

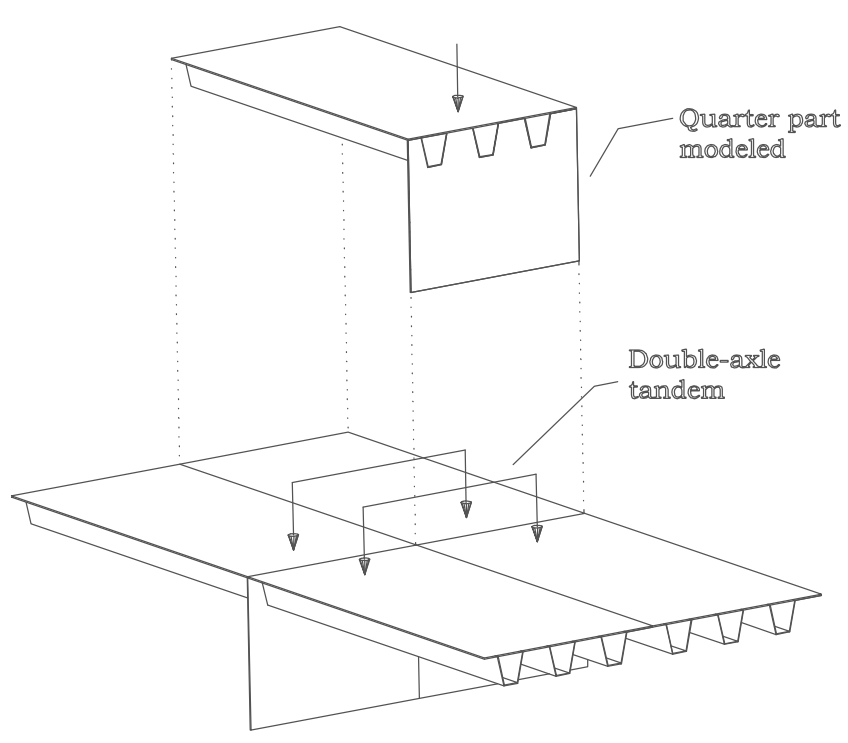

(b)

Figure 10: Figure showing part of bridge deck that is modeled using FE. (a) Detailed drawing showing measurements and showing placing of wheel loads. (b) Due to symmetry only one quarter is modeled (Note all measurements are in millimeters). 


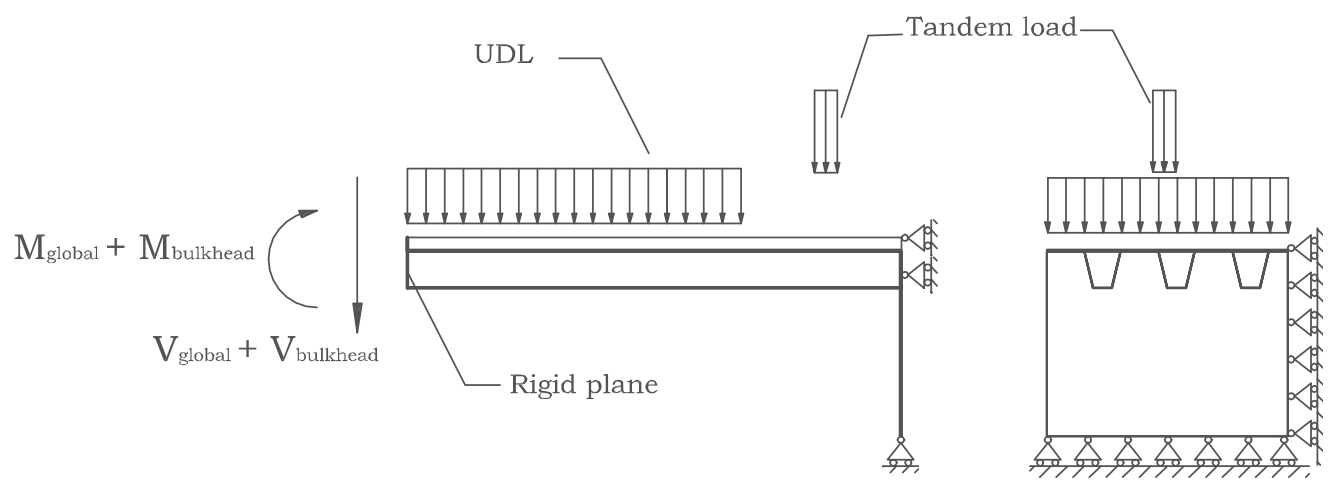

Figure 11: Boundary conditions of bridge deck model. The exterior bending moments and shear forces are applied to a rigid plane. 


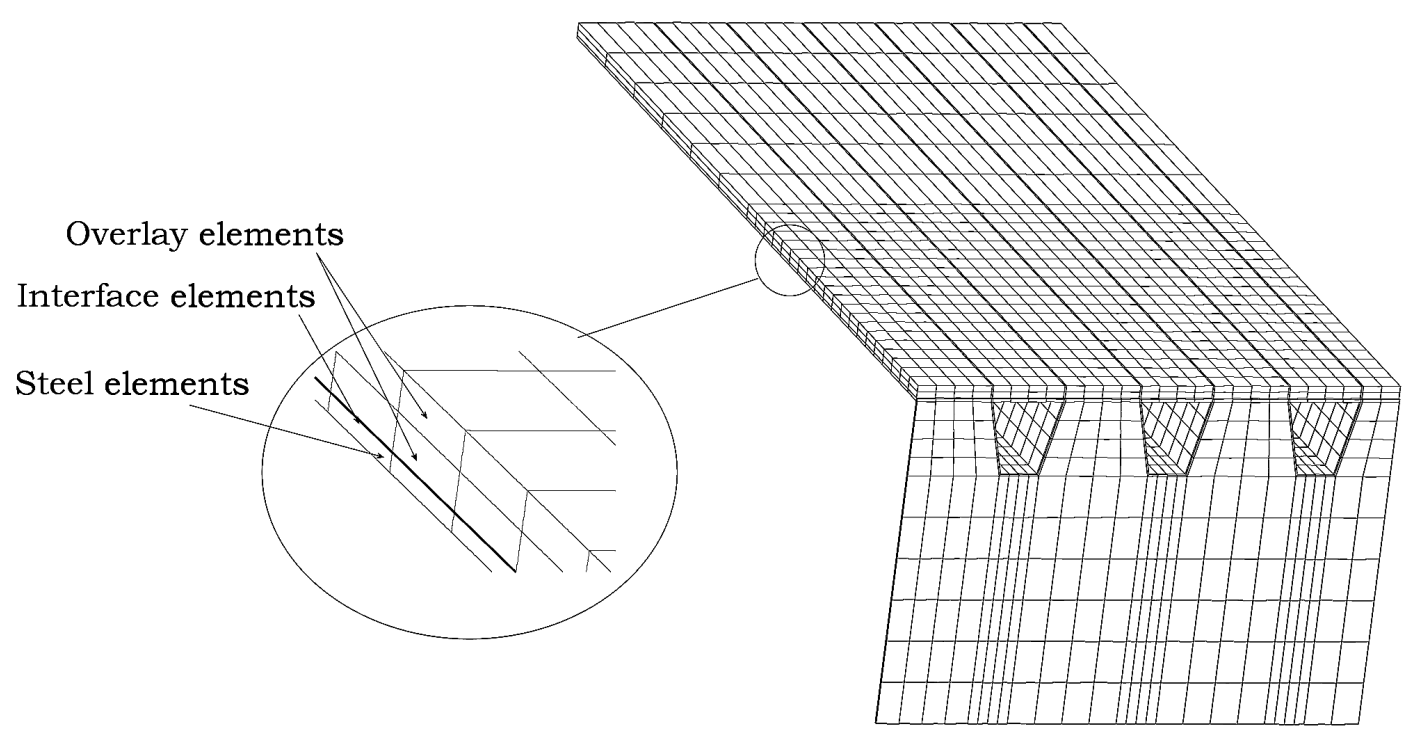

Figure 12: Applied finite element mesh of the deck part. To model steel and overlay a solid 20-node element is used. The connection between the overlay and steel plate is modeled using a 8-node interface element. 

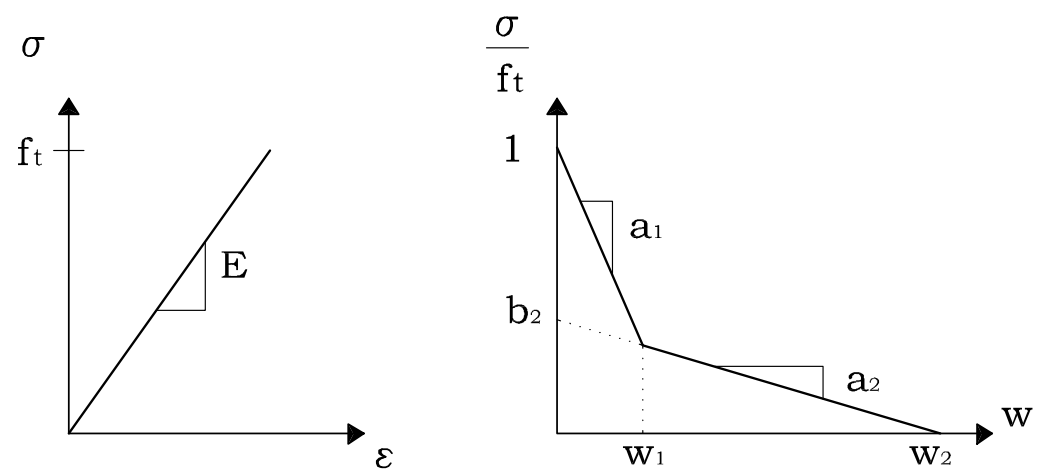

Figure 13: Constitutive modeling of a tension softening material. The material is described in two phases: a linear elastic range, and a bilinear stress-crack opening relationship. 

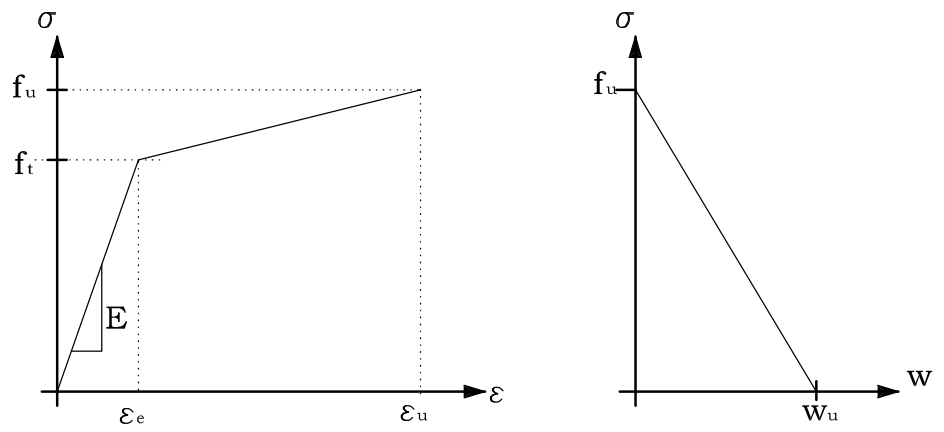

Figure 14: Constitutive modeling of a strain hardening material. The material is described in three phases: a linear elastic phase, a strain hardening phase, and a localization phase. 


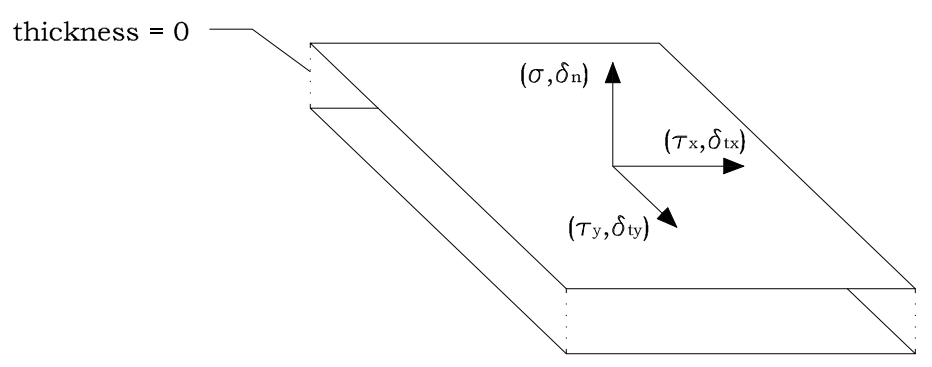

Figure 15: Three dimensional interface configuration. The interface is described by one normal stress and two shear stress components. 

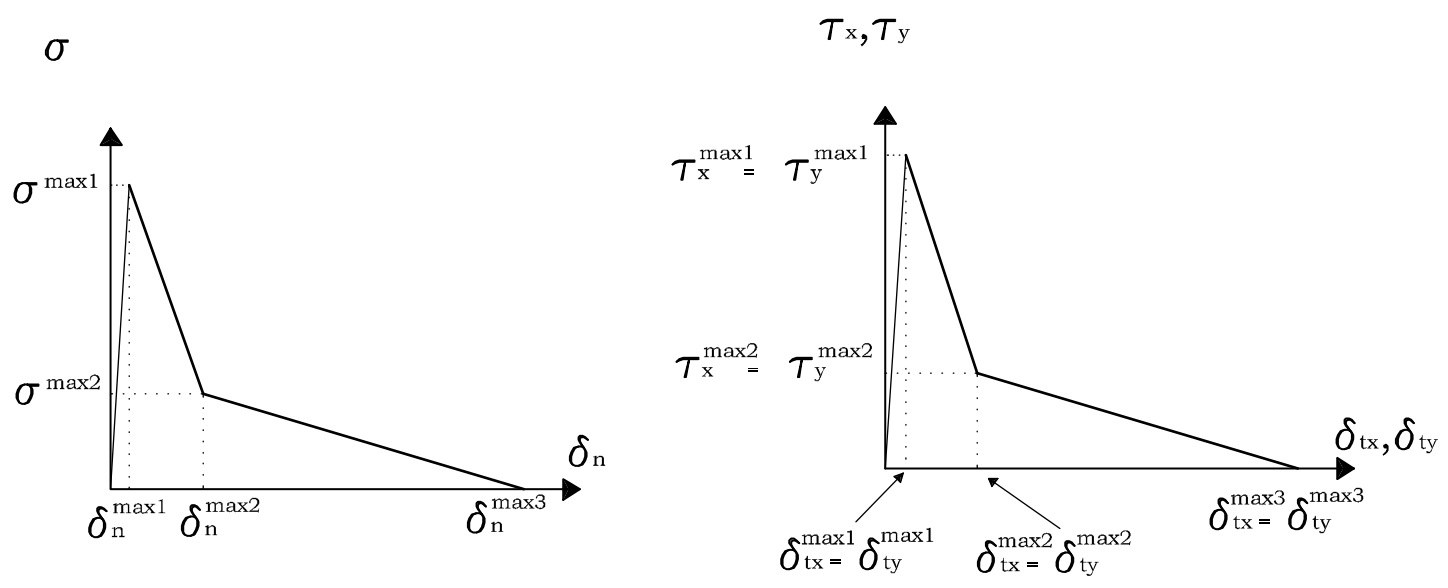

Figure 16: Bilinear stress-crack curves in pure Mode I and II. Until peak stress the curves are uncoupled, and the slopes are assigned large values to model continuous geometry. 


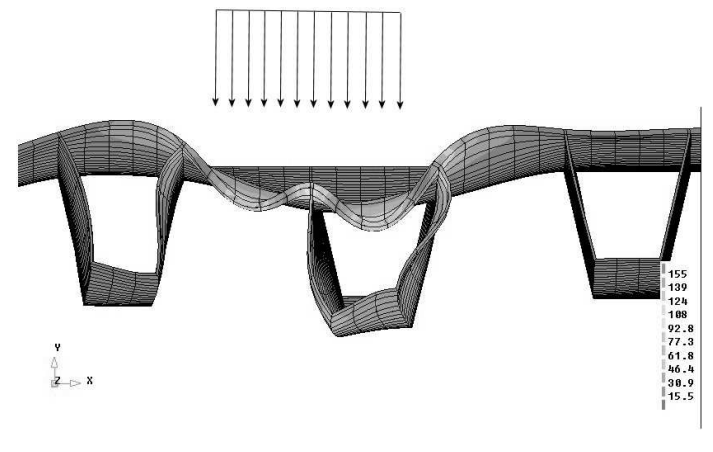

(a)

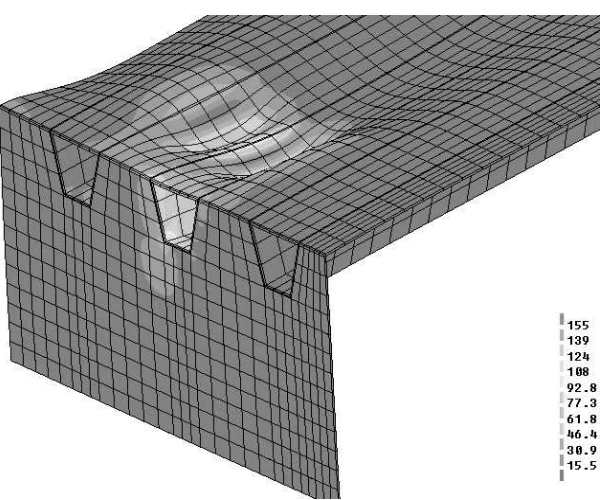

(b)

Figure 17: Deformation plots from linear elastic FE calculations. (a) Wheel load causing transverse bending. (b) Three dimensional view of deformation caused by wheel load. 


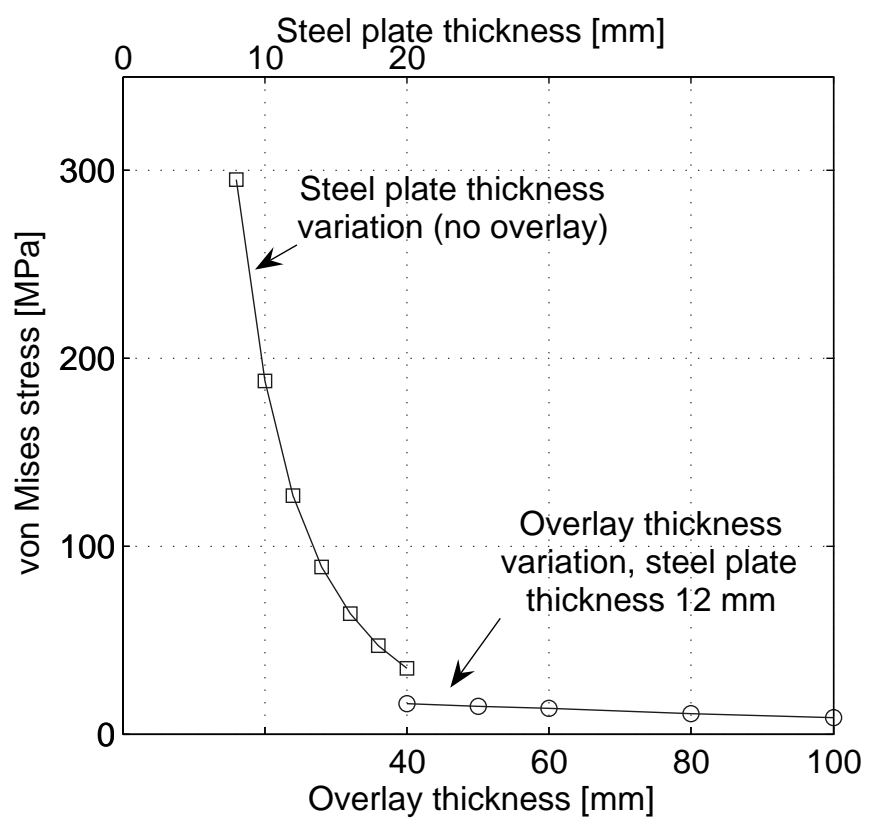

Figure 18: Result of linear elastic studies for traffic and an axle load of $260 \mathrm{kN}$. The left most line represents the von Mises stress of different steel plate thicknesses without an overlay. The other line represents results from a steel plate of $12 \mathrm{~mm}$ and different overlay thicknesses. 


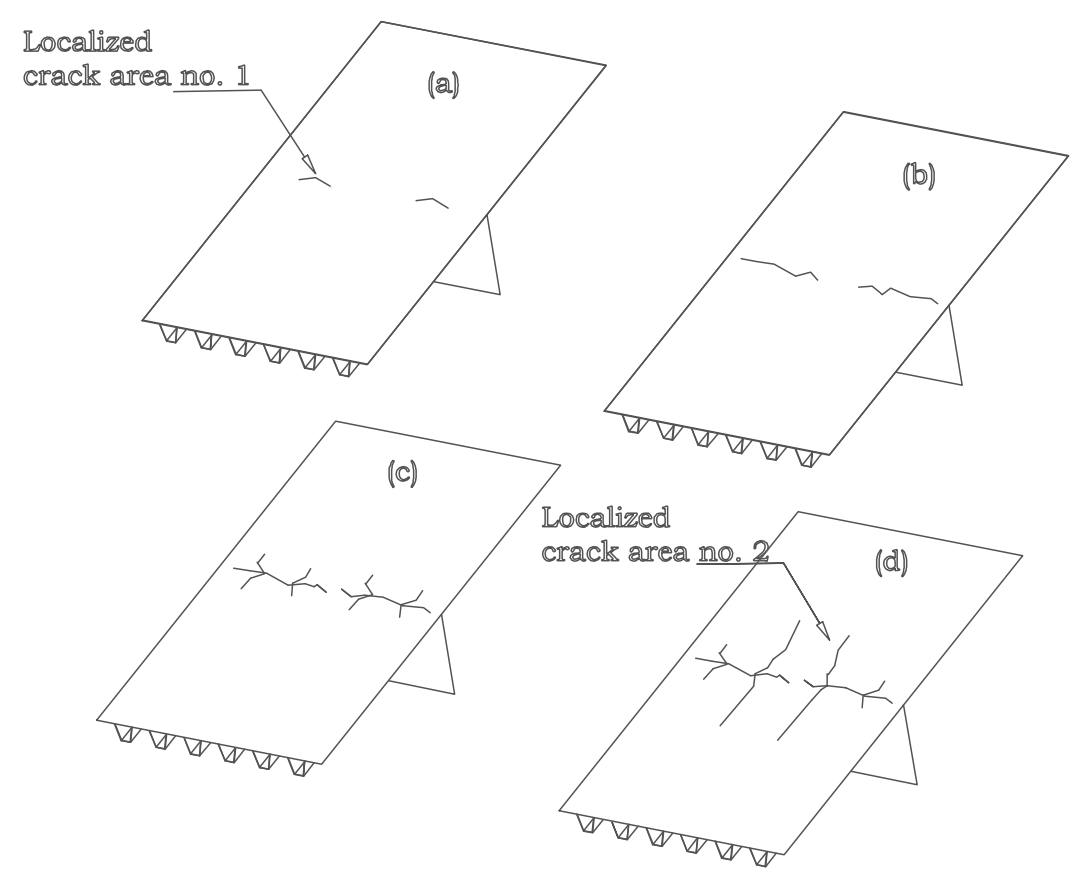

Figure 19: Crack patterns of the overlay (concrete) for traffic and an axle load of: (a) 50 kN, (b) $180 \mathrm{kN}$, (c) $260 \mathrm{kN}$, and (d) $290 \mathrm{kN}$. 


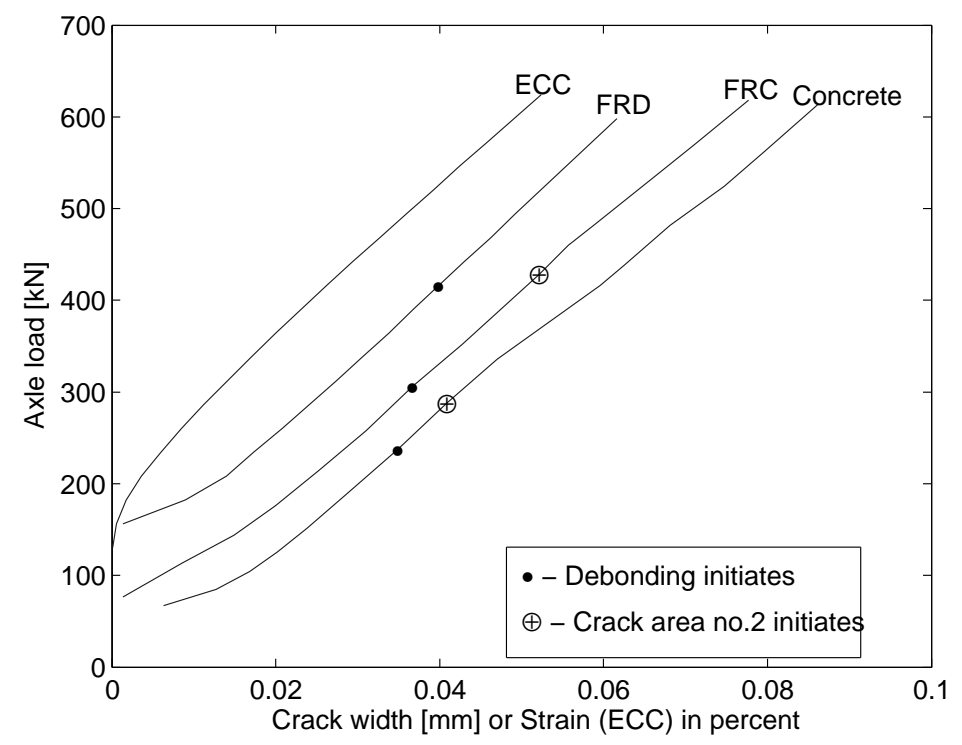

Figure 20: Numerical results of three overlay materials for fixed traffic load and variable axle loading. The results are presented in a load vs. crack width diagram for concrete, FRC and FRD. In the case of ECC material the results are presented as load vs. strain in percent. 


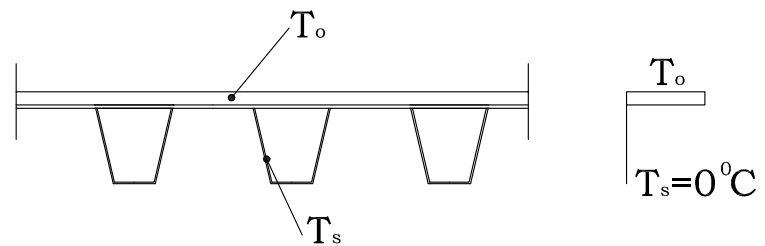

Figure 21: Temperature distribution in bridge deck. 


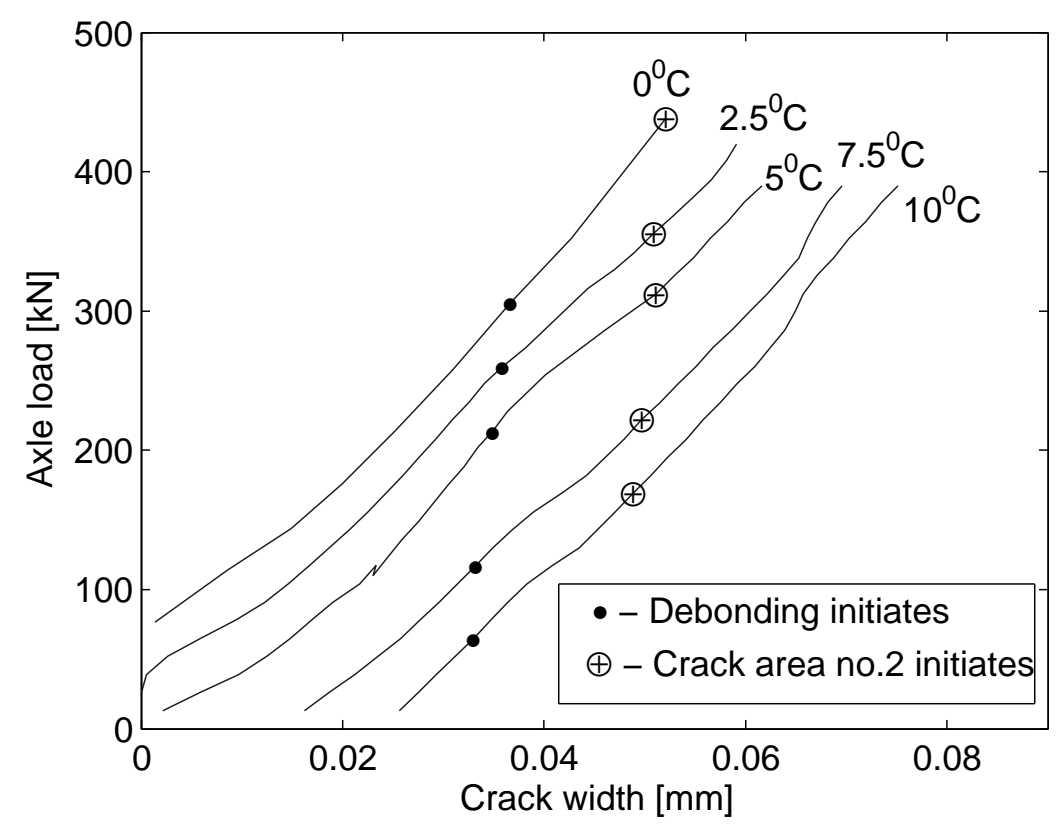

Figure 22: Axle load vs. crack width for a temperatures gradient of $\Delta T=0{ }^{0} \mathrm{C}, 2.5{ }^{0} \mathrm{C}, 5$ ${ }^{0} \mathrm{C}, 7.5{ }^{0} \mathrm{C}$, and $10{ }^{0} \mathrm{C}$ between the FRC overlay (lowest temperature) and the steel deck (highest temperature). 


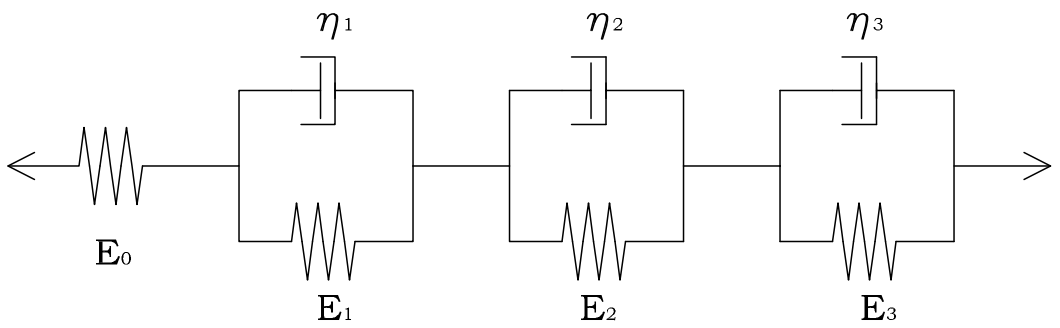

Figure 23: Kelvin chain used in the analysis, composed 4 Kelvin units in serial connection. 

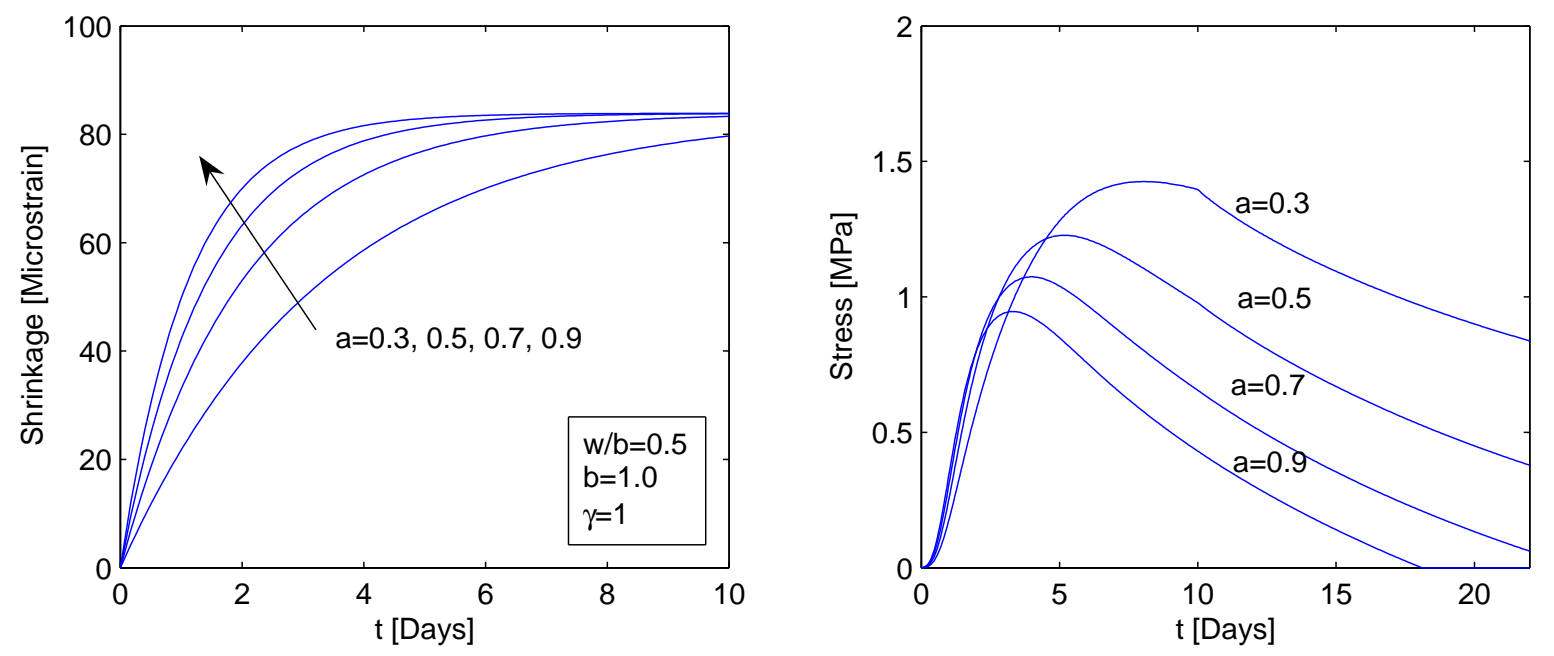

Figure 24: (a) Shrinkage over time using Equation (12). (b) Stresses in overlay for different shrinkage histories. 